\title{
Microglia in Alzheimer's Disease: A Role for Ion Channels
}

\author{
Laura Thei ${ }^{1}$, Jennifer Imm ${ }^{2}$, Eleni Kaisis ${ }^{1}$, Mark L. Dallas ${ }^{1}$ and Talitha L. Kerrigan ${ }^{2 *}$ \\ ${ }^{1}$ Reading School of Pharmacy, University of Reading, Reading, United Kingdom, ${ }^{2}$ University of Exeter Medical School, \\ University of Exeter, Exeter, United Kingdom
}

Alzheimer's disease is the most common form of dementia, it is estimated to affect over 40 million people worldwide. Classically, the disease has been characterized by the neuropathological hallmarks of aggregated extracellular amyloid- $\beta$ and intracellular paired helical filaments of hyperphosphorylated tau. A wealth of evidence indicates a pivotal role for the innate immune system, such as microglia, and inflammation in the pathology of Alzheimer's disease. The over production and aggregation of Alzheimer's associated proteins results in chronic inflammation and disrupts microglial clearance of these depositions. Despite being non-excitable, microglia express a diverse array of ion channels which shape their physiological functions. In support of this, there is a growing

OPEN ACCESS

Edited by:

Alberto Serrano-Pozo

Massachusetts General Hospital,

Harvard Medical School,

United States

Reviewed by:

Yueming $L I$

Memorial Sloan Kettering Cancer

Center, United States

Hai Minh Nguyen,

University of California, Davis,

United States

*Correspondence:

Talitha L. Kerrigan

t.l.kerrigan@exeter.ac.uk

Specialty section: This article was submitted to

Neurodegeneration,

a section of the journal

Frontiers in Neuroscience

Received: 30 March 2018 Accepted: 07 September 2018

Published: 28 September 2018

Citation:

Thei L, Imm J, Kaisis E, Dallas ML and Kerrigan TL (2018) Microglia in

Alzheimer's Disease: A Role for lon

Channels. Front. Neurosci. 12:676.

doi: 10.3389/fnins.2018.00676 body of evidence pointing to the involvement of microglial ion channels contributing to neurodegenerative diseases such as Alzheimer's disease. In this review, we discuss the evidence for an array of microglia ion channels and their importance in modulating microglial homeostasis and how this process could be disrupted in Alzheimer's disease. One promising avenue for assessing the role that microglia play in the initiation and progression of Alzheimer's disease is through using induced pluripotent stem cell derived microglia. Here, we examine what is already understood in terms of the molecular underpinnings of inflammation in Alzheimer's disease, and the utility that inducible pluripotent stem cell derived microglia may have to advance this knowledge. We outline the variability that occurs between the use of animal and human models with regards to the importance of microglial ion channels in generating a relevant functional model of brain inflammation. Overcoming these hurdles will be pivotal in order to develop new drug targets and progress our understanding of the pathological mechanisms involved in Alzheimer's disease.

Keywords: microglia, Alzheimer's disease, ion channel, stem cells, iPSCs

\section{INTRODUCTION}

Alzheimer's disease (AD) is the most prevalent neurodegenerative disorder and accounts for approximately $60-80 \%$ of all dementia cases worldwide (Alzheimer'sstatistics, 2016). Initial studies focussed on trying to identify a genetic basis to the disease (Gatz et al., 2006). Although some $\mathrm{AD}$ cases are caused by defined mutations in one of three genes (APP, PSEN1 and PSEN2) these account for fewer than $10 \%$ of all cases and occur before 65 years of age. The majority of cases are sporadic, have no defined etiology and occurs at or after a mean age of 65. Our understanding has progressed through evidence obtained from large cohort studies identifying genetic variants which are associated with and potentially result in the late onset form of AD (LOAD). These 
genome wide association studies (GWAS) have demonstrated that LOAD is a multifactorial disease with many different genes and single nucleotide polymorphisms contributing to disease onset (Gatz et al., 2006). The most strongly associated gene with LOAD is Apolipoprotein E (APOE), which encodes a polymorphic glycoprotein that is involved in cholesterol and other lipid transport (Poirier, 2005) alongside tissue repair (Huang, 2010) and neuronal growth (Nathan et al., 1994). There are three isoforms of APOE, $\varepsilon 2, \varepsilon 3$, and $\varepsilon 4$ that all correspond to cysteine to arginine substitutions at the amino acid positions 112 and 158 (Zlokovic, 2013). The $\varepsilon 4$ variant confers increased risk of developing $\mathrm{LOAD}$, and each additional copy of the $\varepsilon 4$ allele lowers the mean age of onset (Corder et al., 1993). Neurodegenerative diseases such as AD were traditionally considered to be "neurocentric," however recent findings are challenging this view, implicating glia as primary targets. GWAS studies reveal there have been a number of single nucleotide polymorphisms that are associated with $\mathrm{AD}$ which reside in genes involved in microglial biology. These include common variants such as CR1 (complement receptor 1), CD33 (sialic acid binding Ig-like lectin 3), CLU (clusterin), ABCA7 (ATPbinding cassette, sub family A, member 7), MS4A (membranespanning 4-domain family, subfamily A) and EPHA1 (ephrin type-A receptor 1) (Bertram et al., 2008; Harold et al., 2009; Hollingworth et al., 2011; Naj et al., 2011; Lambert et al., 2013; Zhang et al., 2013), and also more rare coding variants in genes such as TREM2 (triggering receptor expressed on myeloid cells 2) (Guerreiro et al., 2013; Jonsson et al., 2013). TREM2 is a cell surface receptor of the immunoglobulin superfamily that is expressed on microglia (reviewed by Colonna and Wang, 2016). Several variants within TREM 2 appear to significantly increase the risk of developing AD (Jin et al., 2014; Song et al., 2017), in particular rs75932628, an SNP that confers an arginine to histidine change at amino acid 47 (R47H) (Guerreiro et al., 2013; Jonsson et al., 2013). Although TREM2 polymorphisms are associated with a risk of late-onset $\mathrm{AD}$ (Guerreiro et al., 2013), their role in neurodegenerative diseases is controversial. Indeed, recent evidence proposes that the TREM2APOE pathway induces a microglia phenotypic switch from a homeostatic to neurodegenerative phenotype (Krasemann et al., 2017). One of the main functions of TREM 2 is regulating microglial phagocytosis (Hsieh et al., 2009), and as a ligand for TREM2 in microglia, APOE binds to dead neurons and increases Trem2-mediated phagocytosis (Atagi et al., 2015). Interestingly, Kleinberger et al. (2014) showed that missense mutations in TREM2 resulted in impaired phagocytic activity with a reduced level of soluble TREM2 in cerebrospinal fluid (CSF) of AD patients. Indeed TREM2 deficiency has been shown to alter microglial function in both primary microglial cultures and in mouse models of $\mathrm{AD}$ where a decrease in plaque-associated microglia are observed alongside an increase in apoptosis of both resting and activated microglia and reduced phagocytosis (Ulrich et al., 2014; Jay et al., 2015, 2017). These findings suggest that the role of TREM2 in modulating inflammation may be more complex than previously appreciated and may be dependent on the cell type in which it is expressed and the inflammatory context in which it is studied. For a more in depth discussion we refer the reader to the following very comprehensive review articles (Colonna and Wang, 2016; Ulrich et al., 2017; Li and Zhang, 2018).

Microglia are thought to regulate the degree of $A \beta$ deposition by phagocytosis with potentially protective impact on $\mathrm{AD}$ progression (Lee and Landreth, 2010). One striking feature of the behavior of microglia in the $\mathrm{AD}$ brain is their marked clustering around fibrillar $\mathrm{A} \beta$ deposits and they adopt a polarized morphology with hypertrophic processes extending toward plaques (Condello et al., 2015). This aids as a protective physical barrier mechanism through which the $A \beta$ fibrils cannot extend, promoting the formation of highly compact plaque micro regions that have minimal affinity for soluble $A \beta_{1-42}$ (Condello et al., 2015; Yuan et al., 2016). Conversely, areas not covered by microglia processes display "hotspots" with very high soluble $\mathrm{A} \beta_{1-42}$ affinity, leading to markedly concentrated protofibrillar A $\beta 42$ plaque regions (Condello et al., 2015). These "hotspots" are neurotoxic given that adjacent axons develop a greater extent of dystrophy compared to those covered by microglia (Yuan et al., 2016).

On the other hand, most studies in TREM2- deficient ADlike mice have shown reduced number of microglia around $A \beta$ plaques (Jay et al., 2015; Wang et al., 2015). Similar reports suggest that in $\mathrm{R} 47 \mathrm{H}$ human mutants, microglial processes were also unable to form a robust barrier, resulting in a decreased $A \beta$ fibril compaction (Yuan et al., 2016). With the decrease in microglial number, there are less compact $A \beta$ fibrils and a higher ratio of $\mathrm{A} \beta_{1-42}$ plaques (Yuan et al., 2016; Ulland et al., 2017), therefore a deficient rather than an exacerbated microglial response could give rise to the development of sporadic AD. Once activated by pathological triggers, like neuronal death or protein aggregates, microglia extend their processes to the site of injury, migrate to the lesion and initiate an innate immune response (Heneka et al., 2015). Mounting evidence from polymorphisms linking microglial dysfunction to $\mathrm{AD}$ could have a causal role in disease onset and progression and are not just a consequence of neuropathological hallmarks that are characteristic of AD.

\section{THE INNATE IMMUNE SYSTEM IN AD}

Of increasing interest is the involvement of the innate immune system in $\mathrm{AD}$, particularly the role of microglia. Microglia are the resident immune cells in the brain and spinal cord, and play important roles in neurodevelopment, immune surveillance, disease and homeostasis (Nayak et al., 2014). Unlike neurons and other glial cell types, microglia are of haematopoietic lineage, arise early during development (Hutchins et al., 1990), and are derived from erythromyeloid progenitors (EMPs) in the yolk sac (Ginhoux et al., 2010).

Microglia can exist in several morphological/phenotypic states depending on the environment they are in or the factors they are stimulated by. From a highly processed state, the microglia become more amoeboid with increased numbers of intracellular vesicles in preparation for engulfment of foreign particles. These differential states have been termed accordingly as "classical activation," "alternative activation," and "acquired deactivation" 
(Colton, 2009; Colton and Wilcock, 2010). Previous studies defined these states as separate from one another, a profiling index of M1 or M2 phenotyping suggesting a pro- or antiinflammatory state respectively. More recently it has become more apparent that this is derived from the idea that microglia are central macrophages and so must follow by the same "kill or cure" switch seen in these cell types. However, microglia can exist in multiple phases with the same cell producing markers of both pro- and anti- inflammatory components depending on stimulus. Usage of M1/M2 profile terminology fails to capture the heterogeneity of microglia which is a vital to their local and global physiological responses (Mosser et al., 2017).

Classical activation, considered to be pro-inflammatory, is stimulated by IFN- $\gamma$ and is associated with the production of cytokines such as TNF- $\alpha$ and IL- $1 \beta$ and nitric oxide production (Li et al., 2004; Block et al., 2007). On the other hand, alternative activation, is defined by the release of anti-inflammatory cytokines IL-4 and IL-13 and arginase 2. This results in gene expression to promote tissue repair and extracellular matrix reconstruction (Ponomarev et al., 2007; Colton, 2009). Acquired deactivation, is mainly seen in the presence of apoptotic cells and is characterized by the release of IL-10, TGF- $\beta$, IL- 6 , and CSF1 and the production of scavenger receptors (Sawada et al., 1999; Colton, 2009; Colton and Wilcock, 2010; Saijo and Glass, 2011). Microglial phagocytosis relies on specific receptors expressed on the cell surface and their downstream signaling pathways to instigate engulfment of harmful particulates (Figure 1).

Microglia mediate the innate immune response of the brain and are involved in the phagocytosis and clearance of debris, pathogens, and toxins. Their dysfunction and increased $A \beta$ accumulation is universal to $\mathrm{AD}$ patients and not just those with familial APP mutations. This suggests that A $\beta$ build-up is due to poor clearance and not APP proteolysis. Microglia will secrete both pro- and anti-inflammatory factors, which can either be beneficial or detrimental in neurodegenerative diseases. Here exists extensive literature showing that inflammation is integral to $\mathrm{AD}$ progression, facilitating $\mathrm{A} \beta$ deposition, neuronal loss and cognitive deficits. Brains from $\mathrm{AD}$ patients and those from murine models of $\mathrm{A} \beta$ pathology uniformly display high expression of pro-inflammatory cyto- and chemokines including $\mathrm{TNF} \alpha$, IFN $\gamma$, IL- $1 \beta$, and IL-6 (Zheng et al., 2016). IL-1 $\beta$ and TNF $\alpha$ can impair neuronal function by suppression of long-term potentiation of synaptic transmission (LTP) (Rowan et al., 2007). Multiple interactions as well as elevated expression of additional cytokines/chemokines and innate immune receptors favor a pro-inflammatory activation state in $\mathrm{AD}$.

Accumulating evidence demonstrates that inflammasomes, which cleave precursors of interleukin-1 $\beta$ (IL-1 $\beta$ ) and IL-18 to generate their active forms, play an important role in the inflammatory response in the CNS and in AD pathogenesis. The inflammasome is an inducible, high molecular weight, protein complex consisting of the antigen sensor protein NLRP3, adaptor protein ASC, and pro-caspase 1 (Heneka et al., 2015). The complexing of these three components results in cleavage of caspase 1 and instigates a cascade of pro-inflammatory cytokine activation of the IL-1b family. In murine mutants where APP/PS1 was crossed with NLRP3-/- mice, a decrease in cC1 and IL-1 $\beta$ is observed (Heneka et al., 2013).

Conversely an anti-inflammatory profile of microglia also contributes to $A \beta$ pathology. In murine models where IL-10 was either knocked down or knocked out in the APP/PS1 model, a decrease in $\mathrm{A} \beta$ load, increases phagocytosis and reduces microglial APOE expression was observed (Chakrabarty et al., 2015). Further studies showed that this was due to preventing downstream pathways involving Jak1/Stat3 and consequential transcription factor activity (Guillot-Sestier et al., 2015). Additionally, primary microglia treated with fibrillar $\mathrm{A} \beta_{1-42}$ and recombinant IL-10 showed that fibrillar $\mathrm{A} \beta_{1-42}$ is prevented from inducing a pro-inflammatory response of cytokine release including CCL5, CXC10, and TNF $\alpha$, suggesting a push to an anti-inflammatory profile (Chakrabarty et al., 2015).

Therefore, it is pertinent to think that the $A \beta$ activates microglia and results in an innate immune response. Indeed, it has been shown that exposure of microglia to fibrillar $A \beta$ by CD36, a class B scavenger receptor (Coraci et al., 2002), causes the formation of a heterodimer of the TLR4 and TLR6 through NF- $\kappa$ B signaling (Stewart et al., 2010). However, on deletion of MyD88, an adaptor protein essential for downstream TLR signaling, there was a significant decrease in both $A \beta$ load and microglial activation in APP/PS1 mice (Lim et al., 2011). Despite this the MyD88 deletion only resulted in minor improvements in cognitive functions (Lim et al., 2012).

Microglial activation by $\mathrm{A} \beta$ does not necessarily only occur after $A \beta$ deposition but can also occur before plaques are even formed. Maezawa and colleagues have shown that nanomolar concentrations of $A \beta$ oligomers activated microglia and that they required another scavenger receptor, SR-A, and the $\mathrm{Ca}^{2+}$. activated potassium channel KCa3.1 (Maezawa et al., 2011). Another group has also shown microglial activation precedes $\mathrm{A} \beta$ aggregation in APP[V717I] transgenic mice and that this coincides with increased BACE1 activation (Heneka et al., 2005).

Intracellular neurofibrillary tangles of hyperphosphorylated tau are another pathological hallmark of AD. However, the exact mechanisms which lead to the hyperphosphorylation of tau are still unclear. Previously, it has been demonstrated that neuro-inflammation positively correlates with tau aggregation, hyperphosphorylation and neurodegeneration in several models (Sheng et al., 1997; Sheffield et al., 2000; Bellucci et al., 2004, 2011; Ikeda et al., 2005; Yoshiyama et al., 2007).

Microglial activation also precedes tau pathology in the P301S tauopathy model (Yoshiyama et al., 2007). In the triple transgenic model of $\mathrm{AD}$, lipopolysaccharide administration significantly increased tau phosphorylation through toll like receptor 4 signaling (Kitazawa et al., 2005). Interestingly, one paper has demonstrated that microglia may be involved in the propagation of tau pathology through non-synaptic transmission in mammals (Asai et al., 2015). Asai et al. (2015) used two different tau mouse models to show that tau propagation is mediated through microglia which phagocytose tau-positive neurons or synapses and secrete tau protein in exosomes, efficiently transmitting tau to neurons. They also demonstrated that this propagation is sensitive to microglial depletion and inhibition of nSMase 2 activity. On the other 


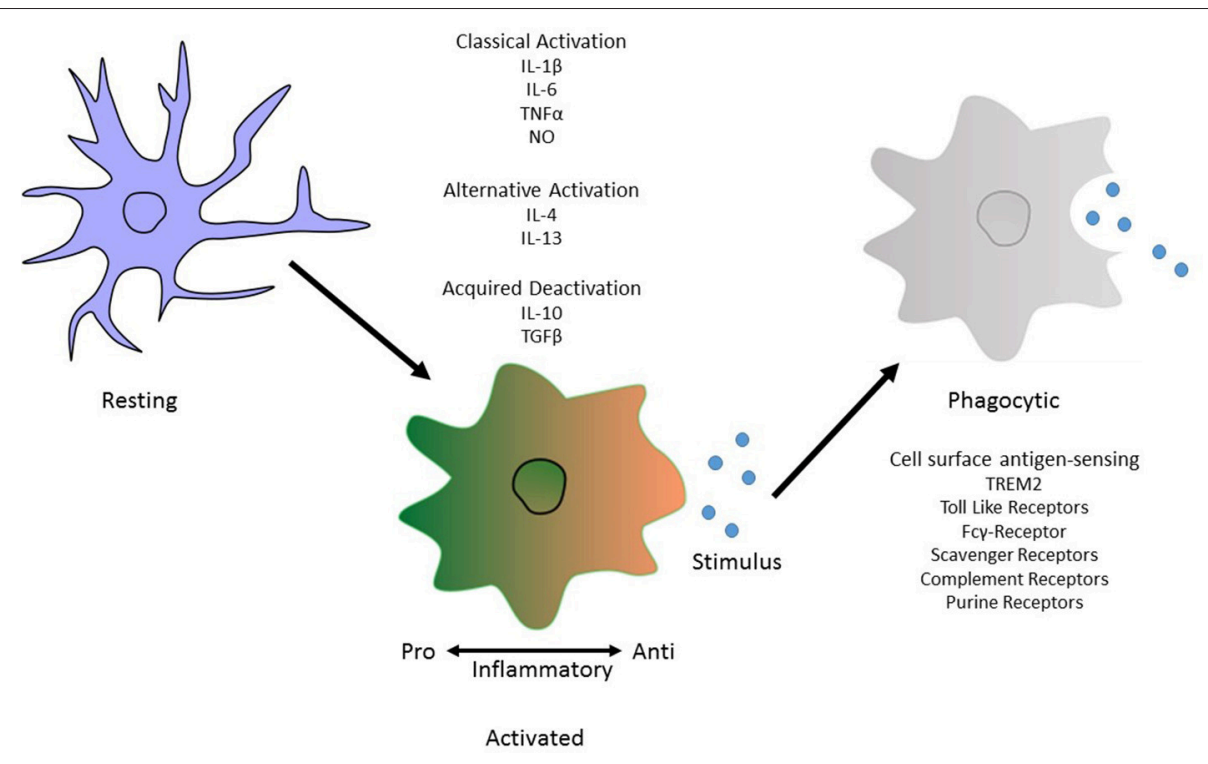

FIGURE 1 | Morphological phenotype of Microglia. An illustration depicting the different phenotypic states. These are "classical activation," "alternative activation," and "acquired deactivation." Classical activation, otherwise considered to be the M1 phenotype and so is pro-inflammatory, is stimulated by IFN- $\gamma$ and is associated with the production of cytokines such as TNF- $\alpha$ and IL-1 $\beta$. Subsequently the alternative activation, or M2 phenotype, defined by the release of anti-inflammatory cytokines IL-4 and IL-13. The third activation phenotype, acquired deactivation, is thought to be a subtype of the M2 phenotype, releases IL-10 and TGF- $\beta$. Activation does not inclusively mean a phagocytic phenotype in microglia. For this to occur, antigen sensing receptors are made available on the cell surface to allow pathogen recognition. In Alzheimer's disease, the best known of these is TREM2 but others include Toll-like receptors and members of the complement system.

hand, significant ablation of microglia in a mouse model of amyloidopathy indicated that $\mathrm{A} \beta$ formation, maintenance and associated neuritic dystrophy was not depended on microglia (Grathwohl et al., 2009). Interestingly, (Krabbe et al., 2013) reported that $A \beta$ may directly affect microglial function. This in vivo study detected a significant inverse correlation between $\mathrm{A} \beta$ plaque burden and microglial phagocytic activity (Krabbe et al., 2013). They found that microglial dysfunction develops early during $\mathrm{AD}$ in an $\mathrm{A} \beta$-dependent fashion and can be restored by interventional anti- $\mathrm{A} \beta$ approaches, such as $\mathrm{A} \beta$ vaccination (Krabbe et al., 2013).

\section{MICROGLIA PHYSIOLOGY AND ION CHANNELS}

Studies have highlighted the importance of microglia in brain ionic homeostasis (Annunziato et al., 2013; Szalay et al., 2016; Shibata and Suzuki, 2017). For example, depletion of microglia results in the loss of potassium chloride induced neuronal depolarisation (Szalay et al., 2016) and the microglia KCa3.1 channel has been proposed as a valid therapeutic target for modulating cortical spreading depression (Shibata and Suzuki, 2017). Therefore ion channels and transporters, regulating ionic flux, are essential regulators of a variety of microglial functions, including proliferation, morphological changes, migration, cytokine release and reactive oxygen species production (Schilling and Eder, 2015). Ion channel expression in microglial cells is tightly regulated, with the expression of most ion channel types noticeably depending on the cells' functional state (Eder, 1998, 2005, 2010; Kettenmann et al., 2011). Despite being non-excitable cells, the plethora of voltage-gated ion channels present in microglia suggests they play a prominent role in both physiological as well as pathological states. Brain inflammation is a characteristic of $\mathrm{AD}$ and numerous studies have demonstrated that microglia can directly interact with neurons to induce inflammation (Hashioka et al., 2012). Due to this interaction, the study of microglial ion channels may shed light on brain inflammation seen in neurodegenerative diseases such as AD (Silei et al., 1999). In this review, we have summarized the most prominent ion channels involved in microglial cells which may contribute to $\mathrm{AD}$ pathology, as demonstrated in Figure 2.

\section{POTASSIUM CHANNELS}

Potassium channels are present in all cells within the body and have many diverse functions. In particular, they are capable of regulating cell excitability and influence action potential waveform. To identify therapeutic targets to modulate microglial activation, numerous studies are addressing the contributions of several $\mathrm{K}^{+}$channels. Based on both their structural and functional properties, $\mathrm{K}^{+}$channels have been subdivided into specific families. They have transmembrane helices (TMs) spanning the lipid bilayer (Kuang et al., 2015). The largest of these consist of $\mathrm{K}^{+}$channels that are activated by membrane depolarisation, with subsequent families consisting of channels that are activated by altered intracellular $\mathrm{Ca}^{2+}$ ions and others that are constitutively active. Based on the structure and function, 


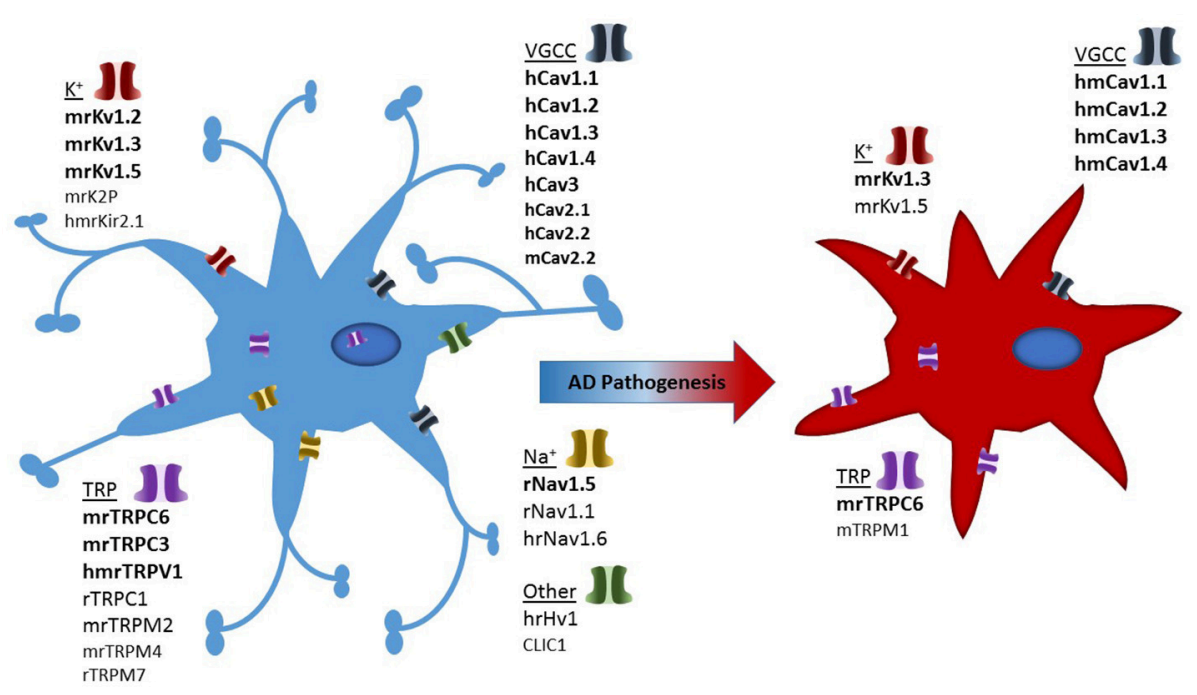

FIGURE 2 | Illustration depicting presence of ion channels observed in microglial models and which of these have confirmed activity in Alzheimer's disease associated microglia. Strength of evidence is depicted in bold to un-bold text. In addition each channel is pre-fixed with the species in which they have been investigated:

h, human; m, mouse; r, rat.

the channels are categorized into three major classes: the voltagegated (Kv) (six TMs), inwardly rectifying (Kir) (two TMs), and tandem pore domain (K2P) (four TMs) channels (Kuang et al., 2015). $\mathrm{K}^{+}$channels are particularly important in microglia since their activation can induce membrane hyperpolarisations, which are essential for driving $\mathrm{Ca}^{2+}$ influx through inward rectifying $\mathrm{Ca}^{2+}$-Release-Activated-Ca ${ }^{2+}$ channels (CRAC) (Kraft, 2015; Nguyen et al., 2017a) ATP-activated P2X receptors (Burnstock, 2015) and other $\mathrm{Ca}^{2+}$-permeable cation channels (Kettenmann et al., 2011).

\section{Voltage-Gated Potassium Channels}

$\mathrm{Kv}$ channels form an exceedingly diverse group, their structure consists of six TMs, of which the first four helices (S1-S4) form the voltage sensor domain (VSD) (Jiang Y. et al., 2003; Long et al., 2007). The last two helices (S5-S6, corresponding to the outer and inner helices in KcsA, respectively) form the pore-forming domain. The VSD senses the membrane potential alteration, and is followed by a conformational change that is coupled to gate the pore-forming domain (Long et al., 2005). In more general terms Kv currents can be classified into showing A-type (inactivating) or delayed rectifier behavior (non-inactivating). The Kv channels present in microglia to date have been summarized in Table $\mathbf{1}$ and mainly comprises of delayed rectifier Kv channels.

$\mathrm{Kv1.2,} \mathrm{Kv1.3,} \mathrm{and} \mathrm{Kv1.5} \mathrm{transcripts} \mathrm{and} \mathrm{protein} \mathrm{have} \mathrm{been}$ detected in both primary rat and mouse microglia (Kotecha and Schlichter, 1999; Khanna et al., 2001; Fordyce et al., 2005; Pannasch et al., 2006; Li et al., 2011). Microglia are widely distributed throughout the brain; however some regions express much higher levels than others (Lawson et al., 1990). The hippocampus, an area particularly affected by $\mathrm{AD}$, is rich with microglia and is especially sensitive to cerebrovascular insults which have been shown to rapidly activate microglia (Wu and Ling, 1998). The reasons for the highly variable expression of Kv channels and the role this plays in non-excitable cells such as microglia are not well understood. It is now known that microglia in culture can express different proteins when compared to microglia in situ in brain slices or in vivo (Boucsein et al., 2003; Butovsky et al., 2014; Yamasaki et al., 2014; Gosselin et al., 2017). Earlier studies mostly used cultured microglia from enzymatically dissociated tissue, thus removing cell- cell contacts and key secretory products such as growth factors affecting $\mathrm{Kv}$ channel expression itself (Kettenmann et al., 1990; Ganter et al., 1992; Draheim et al., 1999). In vitro studies are currently the only way to stimulate microglia in isolation in order to elucidate similarities and differences in how different species respond (Lam et al., 2017).

It is becoming more apparent that altered expression of $\mathrm{Kv}$ channels could trigger the mechanisms underlying microglial polarity and could characterize these microglial states (Saijo and Glass, 2011; Maezawa et al., 2012). In a study on freshly isolated microglial cells, Kotecha and Schlichter (1999) found both Kv1.3 and Kv1.5, the former being associated with proliferating cells and the latter with non-proliferating cells. This shift in microglial activation also results in changes in the physiological properties of the cells (Kotecha and Schlichter, 1999). Resting microglia express Kv1.5 channels and upon activation and proliferation they upregulate Kv1.3 and down-regulate Kv1.5 channels (Pannasch et al., 2006). Kv1.3 channels migrate to the cell surface while Kv1.5 channels are internalized, making Kv1.3 channels not only functionally relevant but highly susceptible to pharmacological manipulation through selective channel blockers. As we have highlighted, majority of microglial studies use animal models, in particular rodents. Lam et al. (2017) found distinct variability between the different rodent models in expressing different $\mathrm{Kv}$ channels. It is also apparent that $\mathrm{Kv}$ channel expression of microglial cells in brain slices from juvenile mice (P5-P9) differs to some extent from that of cells 


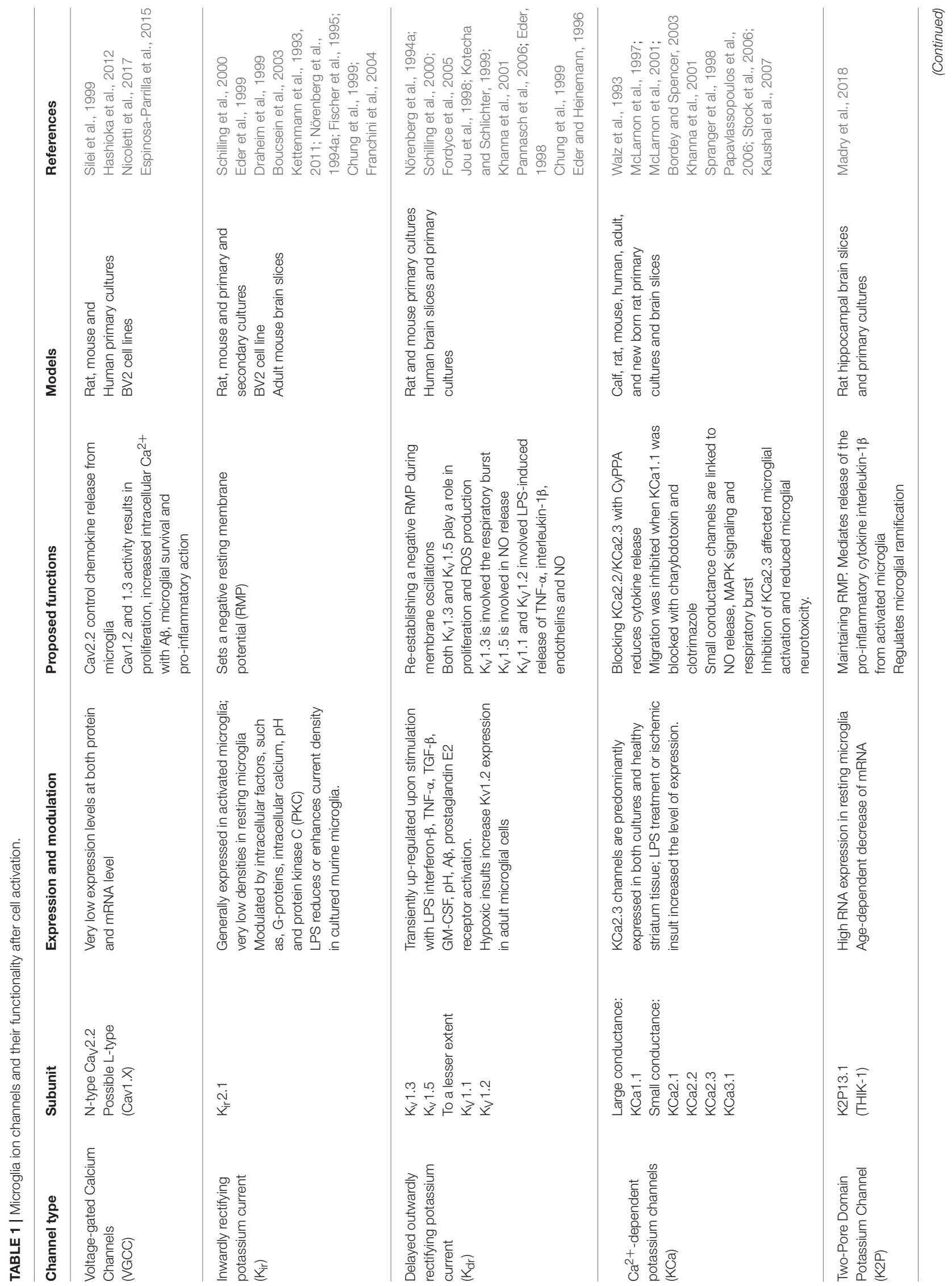




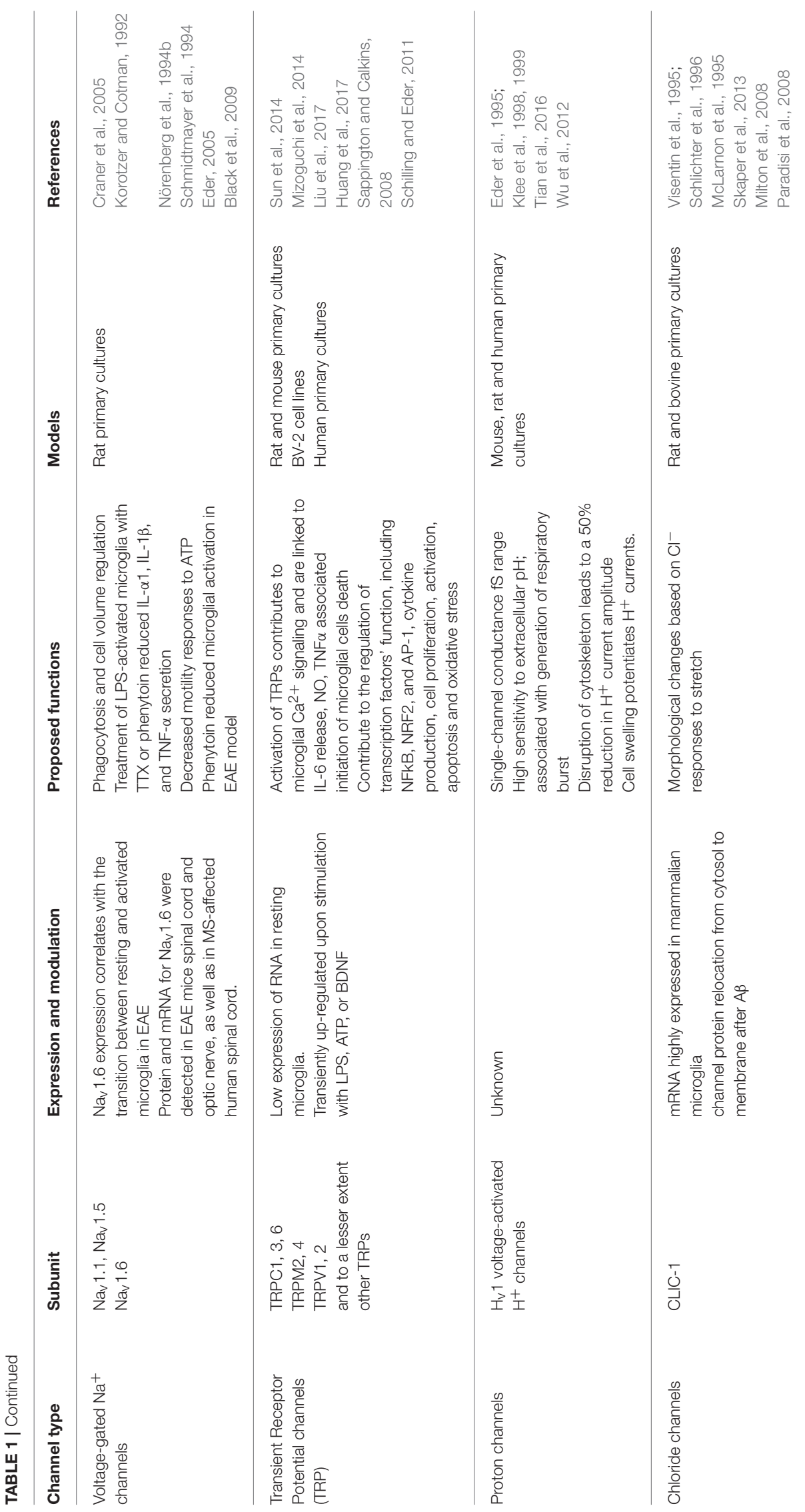


in adult mice (Boucsein et al., 2003; Schilling and Eder, 2007; Menteyne et al., 2009; Arnoux et al., 2013, 2014). The passive membrane properties and $\mathrm{Kv}$ channel expression of microglial cells undergo substantial changes upon aging (Schilling and Eder, 2015). In comparison with microglia of young adult mice, microglial cells of aged mice are characterized by more negative resting membrane potentials, decreased input resistances and upregulated expression of inward rectifier and outward rectifier $\mathrm{Kv}$ channels. Interestingly, the outward rectifier $\mathrm{Kv}$ channel current is strongly age-dependent both in vitro and in vivo (Schilling and Eder, 2015). It is clear from the literature that the way in which we study Kv channel physiology in microglia varies dramatically and depends on the methodology used (Lam et al., 2017).

Further complications include the potential for strain differences in rodents (Becker, 2016), and genetic polymorphisms and epigenetic changes in humans (Boche and Nicoll, 2010). There is considerable debate as to how closely mouse models resemble human responses in inflammatory diseases (Seok et al., 2013; Takao and Miyakawa, 2015). A better understanding of microglial $\mathrm{K}^{+}$channel regulation and expression patterns in neurodegenerative states could also yield targets for drug development using $\mathrm{K}^{+}$channel blockers.

\section{Voltage-Gated Potassium Channels and AD}

Microglia are the key inflammatory cells in AD that mediate neuro-inflammation, and $\mathrm{Kv}$ channels are key regulators of microglial function, in particular Kv1.3 (Rangaraju et al., 2015). In animal models of $\mathrm{AD}, \mathrm{A} \beta$-induced priming of microglial NADPH oxidative activity depends on Kv1.3 channels, however the exact mechanisms that contribute to this priming is still poorly explored (Kotecha and Schlichter, 1999; Schilling and Eder, 2011). It is thought that the activity of $\mathrm{Kv}$ channels lead to membrane hyperpolarization, this Kv1.3 channel-induced membrane hyperpolarisation could enhance $\mathrm{Ca}^{2+}$ influx through Transient receptor potential (TRP) channels (see section Calcium Channels; Schilling and Eder, 2011) aiding in the translocation of PKC and therefore leading to NADPH oxidative priming. Franciosi et al. (2006) demonstrated that the broad spectrum Kv channel inhibitor 4-aminopyridine (4-AP) suppressed microglial activation in vivo and reduced microglia-induced neuronal death (Franciosi et al., 2006). This inhibition using 4-AP, which also blocks Kv1.3 channels, could attribute to inhibition of microglial priming and subsequent reduction of microglial ROS production, supporting a role for Kv1.3 channels as a therapeutic target in $\mathrm{AD}$ (Schilling and Eder, 2011). More recently immunohistochemistry experiments on human brain cortices revealed the presence of Kv1.3 channels in cortical microglia at levels higher than non-AD controls (Rangaraju et al., 2015). This particular study also revealed a "plaque-like" pattern of Kv1.3, suggesting that it may be possible for $A \beta$ to interact with Kv1.3. Interestingly, $A \beta_{1-42}$ oligomers, but not soluble $A \beta$, accelerate the activation and inactivation kinetics of Kv1.3 channels in lipid bilayers without altering channel conductance (Lioudyno et al., 2012). It is possible that altered channel conductance of Kv1.3 channels could affect calcium fluxes in neurons and microglia, however the relevance of this potential $\mathrm{A} \beta$-Kv1.3-interaction remains to be clarified. Another study by Chung et al. (2001) also confirmed that $\mathrm{A} \beta$ was capable of upregulating $\mathrm{Kv} 1.3$ as well as the Kv1.5 channel current density. More recently, low levels of soluble oligomeric $A \beta$ have been reported to upregulate primary cultured microglial activity as well as Kv1.3 at transcript and as protein levels (Maezawa et al., 2017). Electrophysiological studies using whole-cell patch clamp also revealed enhanced outward rectifier current, characteristic of homotetrameric Kv1.3 channels. Pharmacological characterization revealed that the currents were sensitive to the Kv1.3 specific blockers ShK-186 (Tarcha et al., 2012), margatoxin (Garcia-Calvo et al., 1993) and the selective Kv1.3 blocker PAP-1 [5-(4-phenoxybutoxy) psoralen (Schmitz et al., 2005). Oligomeric $A \beta$ further induced a significant increase in Kv1.3 current density compared to unstimulated microglia (Maezawa et al., 2017). Following long-term treatment of an APP/PS1 mouse model, the selective Kv1.3 blocker PAP-1 mitigated some key $\mathrm{AD}$-like phenotypes such as reducing $\mathrm{A} \beta$ deposition as well as restoring hippocampal synaptic plasticity. The observation that pharmacological targeting of Kv1.3 channels in microglia with the selective inhibitor PAP-1 supports PAP-1 as a promising potential for neuro-immunomodulation therapy and the treatment of neurodegenerative diseases such as $\mathrm{AD}$.

The age-dependent changes in microglial Kv1.3 noted in 5xFAD mice followed a similar trend-initially an age-dependent increase, then a substantial decrease between 10 and 15 months of age. We suspect that these changes in $\mathrm{K}^{+}$channel expression form part of the age-related changes in microglial function, documented by several lines of investigation, such as altered responses to $A \beta$ aggregates or downregulation of "sensome" genes (Hickman et al., 2008; Cameron et al., 2012; Heneka et al., 2013; Hickman and El Khoury, 2013; Johansson et al., 2015) ever, this downregulation is not reflected in a human study in which Kv1.3 expression remains robust in microglia, particularly in the later stages of AD (Rangaraju et al., 2015). More recently transcriptomic data from Rangaraju et al. (2018), revealed that Kv1.3 plays a distinct role in disease-associated-microglia in the 5XFAD mouse model (Rangaraju et al., 2018). It is pertinent to say that the evidence presented here from the existing human and rodent studies, show Kv1.3 could be a therapeutic target even at the late stage of the disease. Similar to what we have previously discussed, it appears that the current transgenic models of $\mathrm{AD}$ do not replicate the patterns of microglia activation in human AD. Many potential treatments identified in rodents have failed in human clinical trials. To narrow this translational gap, it is essential to investigate and acknowledge species similarities and differences. With the promises of stem cell therapy and use of iPSCs to model diseases in a dish, pharmacological manipulation on a more directly available human source may reveal further species differences.

\section{Other Potassium Channels}

Recent evidence has suggested that two-pore domain $\mathrm{K}^{+}$ (K2P) channels may play a role in microglia physiology (Madry et al., 2018). Functional investigations provide data to support the involvement of THIK-1 in the cytokine release of microglia in situ. This study revealed two functionally and 
mechanistically distinct modes of microglial motility. THIK-1 regulates microglial ramification, surveillance and interleukin$1 \beta$ release (Madry et al., 2018). This is the first study of its kind to implicate K2P channels in microglia physiology. Future work will provide a better understanding of its role in vivo as well as neuro-inflammatory responses. The impairment of motility of microglial processes that occurs in some pathological conditions, e.g., in models of Alzheimer's disease with $A \beta$ plaque deposition (Koenigsknecht-Talboo et al., 2008; Krabbe et al., 2013; Condello et al., 2015) raises the question of whether the dependence of surveillance on THIK-1 activity can be employed therapeutically for the treatment of AD (Madry et al., 2018). Currently there has been no direct experimental evidence linking THIK-1 to AD.

Another important $\mathrm{K}^{+}$channel that has been shown to play a key role in microglia activation by modulating $\mathrm{Ca}^{2+}$ signaling and membrane potential is calcium-activated $\mathrm{KCa} 3.1$ (also known as IK1, SK4 or KCNN4) channels (Maezawa et al., 2012). This channel is predominantly expressed in microglia and has been a potential target for both industry and academia as a potential drug target for $\mathrm{AD}$ (as reviewed by Maezawa et al., 2012).

The strong inwardly rectifying $\mathrm{K}^{+}$(Kir) channel belong to a family of $\mathrm{K}^{+}$channels that have only two membrane-spanning domains and are responsible for stabilization of the resting membrane potential $\left(\mathrm{V}_{\text {rest }}\right)$ near to the $\mathrm{K}^{+}$equilibrium potential $\left(\mathrm{E}_{\mathrm{K}}\right)$ (Kettenmann et al., 1990; Tsai et al., 2013). Blocking Kir channels depolarizes the cell and decreases the driving force for inwardly transported $\mathrm{Ca}^{2+}$ in microglia. In a study by (Tsai et al., 2013), addition of the $\mathrm{AD}$ drug memantine suppressed Kir as well as depolarized the membrane potential of BV-2 cells. This block of Kir2.1 channels could represent one of the important mechanisms underlying its actions on the functional activities of microglial cells. It remains unclear what the in vivo function of Kir are, an area showing significant promise for AD.

Interestingly, in the transgenic mouse model of $\mathrm{AD}(5 \mathrm{xFAD})$ (Wendt et al., 2017) reported that the impairment in phagocytic function of microglia was due to altered purinergic signaling. They found evidence of altered physiological phenotype only of microglia in $5 x F A D$ mice that were located close to $A \beta$ plaques (Wendt et al., 2017). Supporting the idea that functional and pathological alterations of microglia in $\mathrm{AD}$ may be a consequence of their association with $\mathrm{A} \beta$ plaques. Their detailed study on the 5xFAD model revealed an initial induction of Kir current, followed by subsequent activation of outwardly rectifying currents at a later age. Therefore the induction of Kir current could be considered a first response followed up with outward $\mathrm{K}^{+}$current developing at a later stage of microglial activation, similar to their previous studies (Boucsein et al., 2000; Kettenmann et al., 2011). This data supports the fact that microglia can undergo chronic changes in physiological properties in a disease model over a prolonged period. It appears from the literature that Kv1.3, KCa3.1, and Kir 2.1 inhibitors seem to constitute relatively general anti-inflammatory effects and it could therefore be useful to preferentially target detrimental pro-inflammatory microglia functions associated with neuro-inflammation, such as AD (Nguyen et al., 2017b). A more recent study investigated the effects of $\mathrm{A} \beta$ plaque-dependent morphological and electrophysiological heterogeneity of microglia in the AD mouse model, TgCRND8. Plescher et al. (2018) revealed increased $\mathrm{K}^{+}$currents in plaque-associated but not plaque distant microglia. They believe that this electrophysiological heterogeneity is likely to reflect the different functional states of the microglia in TgCRND8 (Plescher et al., 2018). Their finding that outwardly rectifying currents ( $\mathrm{Kv} 1.3$ ) were confined to a subset of plaque associated microglial cells emphasizes the potential of specific ion channel inhibitors to target only specific (i.e., detrimental) subtypes of microglia in $\mathrm{AD}$ (Plescher et al., 2018).

\section{VOLTAGE-GATED SODIUM CHANNELS}

Sodium voltage channels $(\mathrm{NaV})$ are formed of one pore- $\alpha$ subunit associated with one/more $\beta$-subunits. The $\alpha$-subunit acts as the "voltage sensor" being activated by changes in membrane potential (Payandeh et al., 2011). The $\beta$-subunits have multiple roles, from modulating channel gating and regulating channel expression, to interacting with the cytoskeleton and the extracellular matrix, as cell adhesion molecules (Brackenbury and Isom, 2008). It is now known that there are nine pore forming $\alpha$-subunits of sodium channels, Nav1.1-Nav1.9, encoded by genes SCN1A-SCN11A (Catterall et al., 2005), which associate with one or more non-pore-forming $\beta$ - subunits encoded by SCN1B-SCN4B (Brackenbury and Isom, 2011). In addition to being expressed in cells capable of generating action potentials, sodium channels have also been identified in cells that have not traditionally been considered to be electrically excitable ("nonexcitable cells"), leading to speculation as to their functional role (Pappalardo et al., 2016). Sodium channels contribute to multiple, varied cellular functions in these cells including phagocytosis (Carrithers et al., 2007), migration (Kis-Toth et al., 2011), and proliferation (Wu et al., 2006). Voltage-gated sodium channels have been documented in immune cells such as macrophages (Schmidtmayer et al., 1994; Carrithers et al., 2007, 2009, 2011; Black et al., 2013).

Patch-clamp recordings have since confirmed the expression of functional sodium channels in microglia (Korotzer and Cotman, 1992; Nicholson and Randall, 2009; Persson et al., 2014). A number of voltage-gated ion channels have been identified in microglia, in particularly, voltage-gated $\mathrm{Na}^{+}$channels isoforms (VGSC): Nav1.1, Nav1.5, and Nav1.6 (Craner et al., 2005; Black and Waxman, 2012).

In vitro, microglia derived from mixed glial cultures from neonatal rats, exhibit immunolabeling for Nav1.1, Nav1.5, and Nav1.6, which is most prominent, while Nav1.2, Nav1.3, Nav1.7, Nav1.8, and Nav1.9 are not detectable above background levels (Black et al., 2009). Whole-cell voltage clamp experiments on cultured rat microglia revealed that, depolarization-induced sodium currents were elicited and then completely blocked by $0.3 \mu \mathrm{M}$ TTX, consistent with the presence of functional TTX-S sodium channels (Persson et al., 2014). Similarly, microglia within normal CNS tissues exhibit low levels of Nav1.6 immunolabeling in situ (Black and Waxman, 2012). 
There is a handful of electrophysiological studies of cultures of human microglia derived from native tissue which reports the presence of $\mathrm{Na}^{+}$currents (Nörenberg et al., 1994b; Nicholson and Randall, 2009), however, these are not observed in every laboratory (McLarnon et al., 1997). $\mathrm{Na}^{+}$currents have also been reported in rat microglia (Korotzer and Cotman, 1992). A study in mice provides evidence that Nav1.6, plays a central role in the infiltration and phagocytosis of microglia in experimental autoimmune encephalomyelitis. Furthermore, the same channel is reported to be up-regulated in macrophages and microglia in the lesions of multiple sclerosis patients (Craner et al., 2005). To date there is no direct evidence for the involvement of microglial VGSC in AD. This same group, however, also report the presence of Nav1.1 and Nav1.5 in cultured rat microglia and demonstrate their function in many key microglial processes (Black et al., 2009). Although $A \beta$ is a known activator for microglia, treatment of the human microglial cell line with $A \beta(12 \mathrm{~h}, 10 \mu \mathrm{M})$ there was no significant change in $\mathrm{Na}^{+}$ current or Nav1.5 expression (Nicholson and Randall, 2009). Although there is clear involvement for VGSC in microglial function its role in $\mathrm{AD}$ remain less well defined. This could be due to a number of different contributing factors such as species variation, individual laboratory protocols, as well as non-standardized preparation of exogenous $A \beta$ and $A \beta$ species selection.

\section{TRANSIENT RECEPTOR POTENTIAL CHANNELS}

Transient receptor potential (TRP) channels are non-selective, non-voltage gated cation channels, ubiquitously expressed in mammalian cells. The TRP gene was initially discovered in Drosophilla where mutant gene expressing animals showed impaired vision due to dysregulated $\mathrm{Ca}^{2+}$ influx into photoreceptor cells. TRP channels play important physiological role in cells by their regulation of temperature, chemoception, mechanoception, and nocioception. There are 30 known members of the mammalian superfamily, which can be divided up into six subfamilies, based on amino acid sequence homology. These are: TRPA (Ankyrin); TRPC (Canonical); TRPM (Melastatin); TRPML (Mucolipin); TRPP (Polycystin); and TRPV (Vanilloid). TRP channels are tetramers made of monomeric subunits that include a six trans-membrane (TM) domain with a pore-forming loop between TM 5 and 6 . In addition, their $\mathrm{C}$ - and $\mathrm{N}$-termini are intracellular. Functionally, they act by changing cytoplasmic free $\mathrm{Ca}^{2+}$ concentrations via $\mathrm{Ca}^{2+}$ permeable pore or by modulating ionic movement via changes to the membrane potential. Microglia are evidenced to express some TRP subfamily members, including those of the TRPC, TRPM, and TRPV families.

\section{TRPA}

The smallest of the TRP subfamilies. Its only mammalian member is TRPA1, a mechano- and chemo-sensor. Its name is derived from the $14 \mathrm{~N}$-terminal ankyrin repeats. To date there is no evidence that it is present in microglia, although it's silencing in dorsal root ganglion results in reduced microglia activation following hyperalgesia (Meotti et al., 2017). Similarly, there is no evidence of the presence of TRPML nor TRPP channels being expressed in nor influencing function of microglia.

\section{TRPC}

The TRPC subfamily consists of seven homologs (C1-7), with TRPC2 being exclusively expressed in mouse. TRPC members share a structural motif in the $\mathrm{COOH}$-terminal tail, TRP box, located close to the intracellular border of TM6. In addition, they contain three or four $\mathrm{N}$-terminal ankyrin repeats.

TRPC channels are activated via the stimulation of GPCRs and receptor tyrosine kinases, leading to phospholipase C, inositol 1,4,5-triphosphate, and diacylglycerol production. This stimulation results in a biphasic $\mathrm{Ca}^{2+}$ release with a first phase ER release, followed by sustained $\mathrm{Ca}^{2+}$ influx across the membrane. TRPC channels are known mostly as store operated $\mathrm{Ca}^{2+}$ entry (SOCE) mediators.

In microglia, all seven members have shown RNA expression in in vitro cell line models, although only $\mathrm{C} 1$ and $\mathrm{C} 3$ have been reported in vivo. TRPC1 is a non-selective $\mathrm{Na}^{+} / \mathrm{Ca}^{2+}$ permeable channel with known function in cell survival and proliferation. Their expression is commonly on organelle membranes such as ER and intracellular vesicles. TRPC1 negatively regulates the ORAI1 $\mathrm{Ca}^{2+}$ channel resulting in suppression of $\mathrm{NKkB}$, JNK and ERK1/2 signaling from microglia (Sun et al., 2014).

TRPC3 is widely expressed in the CNS where it has modulation via the growth factor BDNF to induce axonal guidance, neuronal survival, and postsynaptic glutamate transmission. In microglia, pre-treatment with BDNF inhibits $\mathrm{NO}$ and TNF- $\alpha$ upregulation, via sustained $\mathrm{Ca}^{2+}$ influx through upregulated TRPC3 channels at the plasma membrane. Effects were reversed using the siRNA against TRPC3 (Mizoguchi et al., 2014).

\section{TRPM}

The TRPM subfamily has eight mammalian members. Unlike TRPA/C there are no N-terminus anykin repeats, instead having functional protein domains, in addition to the TRP box, in the Cterminus. TRPM's are non-selective cation channels with a verity of cellular functions including temperature sensing, osmolarity, redox, $\mathrm{Mg}^{2+}$ homeostasis, proliferation, and cell death. These channels can be subdivided further into four groups: M1/3; M4/5; M6/7; M2/8. M1, 2, 4, and 7 have all been reported as present in microglia.

TRPM1 was the first to be cloned, in 1998 (Harteneck, 2005), however its function and activation remains unknown. TRPM1 has a high capacitance for splice variance, similarly so with TRPM3-with whom M1 shares strong sequence homology. In murine models of $\mathrm{AD}(5 \mathrm{XFAD} / \mathrm{MHCII}+)$ high levels of $\mathrm{A} \beta$ plaque burden correlated to an increase in TRPM1 gene expression compared to age matched control animals (Yin et al., 2017).

M2 contains an adapted adenosine $5^{\prime}$-diphosphoribose ribose (ADPR)-recognizing Nudix box domain at its c-terminus. It is a redox modulator, activated by reactive oxygen species, 
ADP ribose, $\mathrm{NAD}^{+}$and $\mathrm{Ca}^{2+}$. M2 will mediate the release of lysosomal $\mathrm{Zn}^{2+}$ stores in response to reactive oxygen species, leading to increased cytosolic $\mathrm{Zn}^{2+}$ levels, leading to regulation of cell motility and actin remodeling. Additionally, $\mathrm{Ca}^{2+}$ influx via TRPM2 leads to increased intracellular insulin release in pancreatic $\beta$-cells (Uchida et al., 2011). A number of studies, both in vitro and in vivo confirm TRPM 2 expression and activity in microglia.

In a TRPM2 KO mouse model, microglia show an abolishment of $\mathrm{Ca}^{2+}$ influx after LPS or IFN $\gamma$ stimulation. Activation by these stimuli results in Pyk2-mediated activation of p38 MAPK and JNK signaling as well as an increase in nitric oxide production (Miyake et al., 2014). Similarly studies of MCAO-induced hypoxia in TRPM2 KO mice saw reduced MG activation, reduced cytokine expression and increased brain volume after damage (Huang et al., 2017). Lastly, TRPM2 channels are functionally expressed in the murine microglia cell line BV2. Here these channels have been shown to be involved in LPC-induced p38 MAPK phosphorylation. LPC-induced intracellular $\mathrm{Ca}^{2+}$ increase and inward currents dependent on TRPM2 channels (Jeong et al., 2017).

TRPM4 are non-selective cation channels with a greater affinity for $\mathrm{Na}^{2+}$ over $\mathrm{Ca}^{2+}$. TRPM4 are activated by increased intracellular $\mathrm{Ca}^{2+}$ due to changes in cell membrane potential, ATP, PKC-dependent phosphorylation and calmodulin (CaM) binding to the channels C-terminal CaM domain (Nilius et al., 2005). Functional channels were detected in the mouse primary microglia, both quiescent and active. Here they are thought to mediate membrane depolarisation, in correlation to $\mathrm{Ca}^{2+}$ influx (Beck et al., 2008). Sulfonylurea receptor 1 activates TRPM4 channels in mouse primary microglia. Receptor binding regulates NOS and NO transcription on microglia activation via LPS action at TLR4 (Kurland et al., 2016).

TRPM7, like TRPM6, is a channel-enzyme. It is $\mathrm{Mg}^{2+}, \mathrm{Zn}^{2+}$, and $\mathrm{Ca}^{2+}$ permeable with a strong outward rectifying currentvoltage relationship. In addition to its ionic pore, it contains a tyrosine kinase domain on its N-terminal. Activity at both pore region and kinase domain are implemented to be involved in the channels activity. For example, in rat brain microglia there is a strong increase of intracellular $\mathrm{Mg}^{2+}$ via the channel, however the currents generated were kinase activity-dependant and not due to pore, nor cell, activation (Jiang X. et al., 2003). TRPM7 also plays a role in cell motility. Migration and invasion of M1 (pro-apoptotic) microglia was observed in rat primary and MLS9 microglia after priming with LPS (Siddiqui et al., 2014). In addition, flow cytometry and $\mathrm{Ca}^{2+}$ imaging studies in neonatal mouse microglia saw an increase in intracellular $\mathrm{Ca}^{2+}$ with cell activation by Polyl:C. Increased $\mathrm{Ca}^{2+}$ led to a correlated increase in $\mathrm{TNF} \alpha$ and P38, in a TRPM7-dependent manner.

\section{TRPV}

The final sub-family are the vanilloids, the largest (1-6) and most in depth studies of the TRP channel families. All TRPVs are highly selective to $\mathrm{Ca}^{2+}$. The most well-known is TRPV1 for its actions as a thermosensor (temperatures $>43 \mathrm{C}$ ). V1 mediates heat response and inflammation in addition to nociceptive responses to capsaicin, the main "heat" compound of chili peppers. In addition, application of compounds with a $\mathrm{pH}<5.9$ will shift the temperature gated threshold of these channels to 20-23 C. Heat-mediated activation is shared quality with other TRPV members, specifically 2, 3, and 4. However, these channels are insensitive to capsaicin and $\mathrm{pH}$. V5 and V6 are not thermosensors but have enhanced selectivity to $\mathrm{Ca}^{2+}$ over other monovalent cations. Lastly, all TRPV channels are functionally regulated by their insertion, or retention to the plasma membrane.

TRPV1 has a high protein expression in microglia, with the majority of these channels showing co-localisation to organelles including the golgi, ER, lysosomes, and mitochondria. Interestingly, at resting state there is very little expression at the plasma membrane (Miyake et al., 2015). In a model of rat spinal cord injury, activation of TRPV1 channels, via I.V injection of capsaicin, gave increased expression of SOD1 and pro-inflammatory cytokines from spinal microglia (Talbot et al., 2012). Similar influence on pro-inflammatory markers were observed in retinal microglia where activation of TRPV1 resulted in increased IL-6 and NFkB expression (Sappington and Calkins, 2008). Expression of TRPV1 protein and function was confirmed in HMO6 human microglial cell line. Application of capsaicin resulted in increased intracellular $\mathrm{Ca}^{2+}$, and subsequently cytochrome $\mathrm{C}$ and cleaved caspase 3 release (Kim et al., 2006). Together this suggests a strong role of TRPV1 in the pro-inflammatory profile of microglia.

Little is known about the other TRPV channels in microglia, although an RNA-based analysis by Raboune et al. (2014). showed upregulation of TRPV1-4 in BV2 cells following cell activation by $\mathrm{N}$-acyl amide.

\section{Microglial TRP Channels in AD}

$\mathrm{A} \beta$ accumulation, one of the major hallmarks of $\mathrm{AD}$, commonly results in excitotoxicity and cell death via the disruption of normal $\mathrm{Ca}^{2+}$ homeostasis and release of pro-inflammatory factors such as ROS, NO, and cytokine release. The previous section highlights the role of TRP channels in intracellular $\mathrm{Ca}^{2+}$ regulation as well as differentially switching the phenotype of microglia between M1 (pro-apoptotic) and M2 (pro-survival). Despite this there is little research into glial TRP channel activity in $\mathrm{AD}$, with most of the focus being on neuronal responses.

$\mathrm{A} \beta$ treatment of $\mathrm{BV}-2$ cells gave an upregulation of protein and mRNA for TRPC6 that is dependent on NFkB activity. When these cells had TRPC6 knocked down via siRNA, the condition media was neuroprotective to cultured hippocampal cells compared to sham BV2 cells. Neuronal influence of TRPC6 activates via an upregulation of COX2 downstream (Liu et al., 2017). By using familial AD mouse models- APP23 and $5 \mathrm{XFAD}$, plaque associated microglia from these animals were homogenized and run through flow cytometry to observe upregulated genes. From these TRPM1 was pulled out, however its role in AD remains unclear (Yin et al., 2017). BV2 cells treated with either fibrillary or soluble $A \beta$ saw high levels of ROS which was attenuated with simultaneous application of TRPV1 via I-RTX (Schilling and Eder, 2011). 


\section{CALCIUM CHANNELS}

Plasma membrane calcium channels are subdivided into three main groups according to their manner of activation; the voltagegated calcium channels (VGCCs), the store-operating calcium channels (SOCs) and the receptor-operated calcium channels (ROCs). VGCCs specifically, play a vital role in maintaining calcium homeostasis, with important roles in cellular processes such as neurotransmission, control of gene expression, hormone secretion and cell apoptosis (Ertel et al., 2000; Valerie et al., 2013). Therefore, developing therapeutics that target these channels may be of benefit in treating various diseases of the CNS, such as AD. Structurally VGCCs consists of the $\alpha 1$ pore-forming subunit consisting of four transmembrane domains, the cytoplasmic $\beta$ subunit, the peripheral $\alpha 2 \delta$ and occasionally the $\gamma$ accessory subunit (Ertel et al., 2000). VGCCs are divided into subfamilies according to their poreforming subunit; the high voltage-activated channels known as Cav1 (Cav1.1-1.4) and Cav2 (Cav2.1-2.3), and the low voltage-activated Cav3 channels (Cav3.1-3.3) (Ertel et al., 2000).

\section{Voltage-Gated Calcium Channels}

To date, evidence suggesting the existence of microglial VGCCs and their involvement in $\mathrm{AD}$ is limited. Although numerous studies, mainly via electrophysiology and Fura-2 calcium imaging, have proven that various agents such as A $\beta$, ATP, and $\mathrm{K}^{+}$, cause an increase in intracellular $\mathrm{Ca}^{2+}$, the mechanism by which this phenomenon occurs is still under debate (Korotzer et al., 1995; McLarnon et al., 1999; Valerie et al., 2013). Thus, there is no clear indication of the existence of microglial VGCCs or whether the increase in intracellular $\mathrm{Ca}^{2+}$ is due to other factors such as ion exchange transporters or opening of intracellular stores (Korotzer et al., 1995; McLarnon et al., 1999; Valerie et al., 2013).

The majority of human studies, have investigated the presence and functionality of VGCCs in human glioblastoma cell lines, consisting of a mixed culture of glial cells, including astrocytes and microglia. Therefore, a major limitation of human in vitro studies, is that identifying VGCCs in glioblastoma cells does not necessarily indicate the presence of these channels in microglia. For instance, Valerie et al. (2013), demonstrated that pharmacological inhibition via the calcium channel blocker (CCB) mibefradil, or siRNA-induced downregulation of the Cav3 channel (T-type current) in human glioblastoma cell lines, led to cell apoptosis. Additionally, Nicoletti et al. (2017) demonstrated that Cav2.1 and Cav2.2 are involved in glial proliferation, through using of pharmacological tools (Nicoletti et al., 2017). Furthermore, via the use of an Iba-1 antibody, a marker of inflammation, and immunohistochemistry, in an in vivo rodent glioblastoma model (GL261 glioma cells), it was revealed that the degree of Iba-1 positive microglia had increased following $\mathrm{N}$-type inhibition. This highlights a role of microglial VGCCs not only in cell proliferation and microglial survival, but also in inducing their pro-inflammatory action (Nicoletti et al., 2017). Evidence from human glial cells, demonstrates that VGCCs are expressed in human microglia, and that microglia VGCCs may also have a role in neurotoxicity (Hashioka et al., 2012). Prior to 48-h treatment with LPS and IFN- $\gamma$ to induce inflammation, primary human microglial cells were treated with the L-type blocker nimodipine, significantly reducing neuronal toxicity induced by the microglia (Hashioka et al., 2012). In contrast to other studies, Hashioka et al. (2012) provided more conclusive evidence in indicating the presence of microglial VGCCs due to the use of primary human microglia and not a cell line consisting of a mixed glial population. A 1999 study demonstrated a more direct involvement of microglia VGCCs with progression of AD by investigating how $\mathrm{A}_{25-35}$ alters $\mathrm{Ca}^{2+}$ signaling in human microglia (Silei et al., 1999). Incubation with $\mathrm{A} \beta$ caused an increase in microglia proliferation and additionally an increase in intracellular $\mathrm{Ca}^{2+}$ levels (Silei et al., 1999). As no significant increase in microglial intracellular $\mathrm{Ca}^{2+}$ levels were observed when microglia were incubated in $\mathrm{Ca}^{2+}$-free media, it was suggested that this change was due to VGCC-mediated $\mathrm{Ca}^{2+}$ influx (Silei et al., 1999). This was verified via co-incubation of microglia with $A \beta$ and the CCBs verapamil, nifedipine and diltiazem which lead to a half-reduction in intracellular levels (Silei et al., 1999). Moreover, incubation of peptide-treated microglia with nifedipine not only lead to a reduction in intracellular $\mathrm{Ca}^{2+}$, but also significantly prevented the increase in microglia proliferation induced by the peptide. Therefore, this study proposes that $\mathrm{A} \beta$ has the ability to increase microglia number and also induce their activation and consequently inflammatory action, through a VGCC manner (Silei et al., 1999).

In contrast to human studies, the majority of studies using animal models, have not provided conclusive evidence to indicate the existence and activity of VGCCs in microglia (Toescu et al., 1998; Silei et al., 1999).

A possible explanation for this, could be that microglial VGCC expression and activity is species-dependent. For instance, studies have shown that rodent microglia can express very low levels of VGCC activity which may even remain undetected (Toescu et al., 1998). Toescu et al. (1998), demonstrated that adding ATP to microglia isolated from murine cortex lead to a significant increase in intracellular $\mathrm{Ca}^{2+}$ levels. In contrast, $\mathrm{KCl}$ induced microglial depolarisation, did not lead to an increase in intracellular $\mathrm{Ca}^{2+}$ thus it was proposed that increased $\mathrm{Ca}^{2+}$ levels involved VGCC independent pathway (Toescu et al., 1998). Prolonged elevation in intracellular $\mathrm{Ca}^{2+}$ levels can activate pathways involved in regulation of gene expression such as the $\mathrm{Ca}^{2+}$-calmodulin pathway, and therefore altered $\mathrm{Ca}^{2+}$ signaling in microglia may occur as a pathway for microglia activation and may even induce the progression of various pathological conditions such as $\mathrm{AD}$ (Toescu et al., 1998).

Although the majority of animal model studies have not definitively proven the existence of the channels in microglia, a few were able to provide some evidence indicating their existence. In a study carried out in 2014 by Saeugusa and Tanabe, where rodent lines were created where expression of Cav2.2 was suppressed, they indicated dynamic modulation of microglia Cav2.2 in regulation of pain related behavior. (Saegusa and Tanabe, 2014). Saeugusa and Tanabe also highlight neuronal 
and microglial crosstalk, in controlling response to pathology (Saegusa and Tanabe, 2014). A more recent study investigated how microglial activation, verified by immunostaining and morphological changes, alters the activity of the L-type currents in an in vivo animal model for neurodegeneration, and in the in vitro BV2 cell line (Espinosa-Parrilla et al., 2015). Comparison of microglia before and after LPS and IFN $\gamma$ stimulation revealed differences as seen via immunostaining and molecular approaches such as western blotting and PCR (Espinosa-Parrilla et al., 2015). Additionally, as depolarisation of LPS/IFN $\gamma$ treated microglia demonstrated changes in intracellular $\mathrm{Ca}^{2+}$ by treatment with either nifedipine or Bay K8644 (agonist), it was suggested that VGCCs, may form part of the mechanism involved in the activation of microglia, inducing their pro-inflammatory action (Espinosa-Parrilla et al., 2015).

To summarize, even though human microglia studies have proposed the existence of functional VGCCs, the majority of the studies were carried out in mixed glial cell lines. Additionally, animal studies have either demonstrated very low expression of VGCCs in microglia or were not able to prove their existence, either at a functional or expression level (protein and mRNA). Thus, due to the limited and contradicting evidence on human and rodent microglial VGCC existence, the use of human induced pluripotent stem cells (iPSCs) may allow a more effective study of microglial ion channel role in neuro-inflammation observed in neurodegenerative diseases such as AD.

\section{CHLORIDE CHANNELS}

Chloride channels are a diverse superfamily of channels proteins, incorporating the volume regulated chloride channels, the $\mathrm{ClC}$ proteins, $\mathrm{Ca}^{2+}$ activated chloride channels, CFTR and maxi chloride channels (Alexander et al., 2017). Studies have identified $\mathrm{Cl}^{-}$channels in rat (Visentin et al., 1995; Schlichter et al., 1996), bovine (McLarnon et al., 1995) and human microglia (McLarnon et al., 1997). These have mainly been based on pharmacological studies using a range of $\mathrm{Cl}^{-}$channel blockers (e.g. nifluemic acid). Pharmacological modulation of $\mathrm{Cl}$ - channels indicates a role for in the regulation of microglia process outgrowth (Hines et al., 2009). However, the lack of specific pharmacological tools has hindered our progress in identifying specific channel entities, and indeed their contribution to microglia physiology. This is backed up with a lack of experimental evidence as to the molecular identity of the channels that have been suggested to be responsible for experimental observations. While the molecular identity remains to be resolved, evidence indicates that is a similar fashion to $\mathrm{Cl}^{-}$currents within lymphocytes, microglia $\mathrm{Cl}^{-}$conductance are responsive to stretch (Lewis et al., 1993; Steinert and Grissmer, 1997). Interestingly CLIC1 an intracellular chloride channel has received some attention with relation to amyloid pathology (Novarino et al., 2004; Milton et al., 2008; Paradisi et al., 2008). This suggests a role for modulation of chloride conductances in microglial generation of reactive oxygen species, but robust evidence for this is lacking in relevant in situ models of microglia.

\section{VOLTAGE GATED PROTON CHANNELS (HV1)}

Voltage-gated proton channels $\left(\mathrm{H}_{\mathrm{V}} 1\right.$; Alexander et al., 2017) reportedly consist of 4 proton sensitive transmembrane domains which are sensitive to both membrane depolarisation and transmembrane $\mathrm{pH}$ gradient (DeCoursey, 2008; Capasso et al., 2011). There is widespread expression of these channels within the central nervous system, highlighting both regional and cellular variation (Eder et al., 1995; McLarnon et al., 1997). Functional evidence comes from both studies carried out on murine microglia (Eder et al., 1995; Klee et al., 1998, 1999), rat (Visentin et al., 1995), and human microglia (McLarnon et al., 1997). There is also evidence to link Hv1 to both microglia polarity and brain responses to stroke (Wu et al., 2012; Tian et al., 2016). This could be pertinent given the link between hypoxia and Alzheimer's disease (Peers et al., 2007). However, one drawback from these studies is the use of culture preparations. This is pertinent given that work on brain slices was unable to detect any $\mathrm{H}^{+}$conductance in situ (De Simoni et al., 2008). This again raises the question about membrane properties in cultured preparations in contrast to in situ set ups. In addition there are questions around the physiological role of these channels when present in microglia (Eder and Decoursey, 2001) It is well established that microglial reactive oxygen species contribute to neuronal cell death in AD (see review Block et al., 2007). This process likely involved the build-up of protons within microglia, which will impact on the flux through Hv1 channels. However, a direct demonstration of the involvement of $\mathrm{H}_{\mathrm{V}} 1$ in this process is lacking. There is greater evidence to indicate the involvement of other channels (e.g., Kv1.3) which are discussed elsewhere in this article.

\section{MODELING MICROGLIAL INVOLVEMENT}

To fully understand a disease and its etiology it is necessary that extensive modeling takes place. By tradition this has been through the use of a number of different model systems including both animal (murine) models and primary patient cell lines. Currently in $\mathrm{AD}$ research there is a large focus on the use of animal models, particularly transgenic mice (McGowan et al., 2006), as a lot is understood about their genetics and the availability of well-characterized genetic manipulation techniques in this organism. Not only this, mice are more closely phylo-genetically related to humans than other model systems such as Caenorhabiditis elegans or Drosophila melanogaster. The genetic similarities between humans and mice means that they have utility in studying the familial aspect of $\mathrm{AD}$ by using transgenic mice that contain mutations in the APP and PSEN genes. There are over 100 different transgenic mouse models available to study the familial aspect of $\mathrm{AD}$, with some models containing five different mutations in the APP and PSEN genes (Oakley et al., 2006).

As it is widely accepted that $\mathrm{A} \beta$ plaques and neurofibrillary tangles cause neuro-inflammation, models which overexpress mutant human versions of APP have been shown to present 
microglial activation (Bornemann et al., 2001; Wright et al., 2013). In addition to this it was shown that there were significant increases in $\mathrm{CD} 38$-positive microglia before $\mathrm{A} \beta$ deposition which also correlated with neuronal cell death in the CA1 region of the hippocampus (Wright et al., 2013). The inflammatory processes of in another APP mouse model, Tg2576, were investigated by looking at individual microglial cells using in vivo multiphoton imaging. Meyer-Luehmann and his colleagues showed that $A \beta$ plaques can form within days and once formed it only takes 1-2 days before microglial cells begin to aggregate around the depositions. Alongside this accumulation of microglia is accompanied by changes to neurite morphology (MeyerLuehmann et al., 2008). Whilst these have their advantages, they also have a number of limitations. These types of models do not accurately recapitulate human pathology as they do not develop the robust tauopathy or neuronal cell death that is seen in human disease without the addition of extra transgenes such as tau (Ribé et al., 2005).

The triple-transgenic model of $\mathrm{AD}$, which contains the APP $_{\text {SWE }}$, Presenilin-1 (PSEN M146V $_{\text {V }}$ ) and tau mutations (tauP301L) offers the advantage that they develop $A \beta$ plaques, tau tangles, synaptic dysfunction and LTP deficits which all manifest in an age-related manner (Oddo et al., 2003). Janelsins et al. demonstrated that this model shows a 14.8 fold increase of TNF$\alpha$ and 10.8 fold increase in MCP-1 mRNA in 6 month old triple transgenic mice when compared to 2 month old mice. However these increases were only seen in the entorhinal cortex and could not be replicated in the hippocampus, suggesting that different cell types or environments may be responsible for the differential transcript levels and inflammatory responses in these disease relevant brain regions (Janelsins et al., 2005).

Mouse models containing just tau mutations have also been investigated in terms of neuro-inflammatory response and they too also display microglial changes (Wes et al., 2014; Cook et al., 2015). For example, the P301S tau model whose neurons develop bundles of hyperphosphorylated tau also have significant increases in inflammatory molecules such as IL- $1 \beta$ and COX2 within the tau-positive neurons. Alongside this they also demonstrated that there were activated microglia throughout the brain and spinal cord, but that these microglia could be predominantly found surrounding the tau-positive neurons (Bellucci et al., 2004). Interestingly, this microglial activation was shown to begin before neurofibrillary tangle formation, but could be ameliorated using an immunosuppressive drug, FK506, early in life increasing life span and attenuating tau pathology (Yoshiyama et al., 2007). One important thing to bear in mind that mutations in tau do not cause AD but instead cause frontotemporal dementia. So whilst these models can provide useful information about how mutations in tau can cause cellular dysfunction and neurodegeneration they do not completely replicate $\mathrm{AD}$ in terms of other pathological markers (Wolfe, 2012).

Whilst proven useful for modeling autosomal disease, such as the familial form of $\mathrm{AD}$, as previously mentioned, these murine models do not accurately recapitulate $\mathrm{AD}$. A more promising avenue for modeling complex diseases, such as sporadic $\mathrm{AD}$, is through the use of stem cell technology. Embryonic stem cells
(ESCs) are derived from the inner cell mass, or blastocyst, of an embryo and can differentiate into any cell in the body (Evans and Kaufman, 1981). Despite their many potential uses, the ethical issues surrounding the use of embryo-derived cells are numerous. However, recent advances in stem cell technology have meant that it is now possible to derive stem cells from differentiated adult cells/tissue. Takahashi et al. showed it was possible to use ectopic transcription factors to induce pluripotency and ESC properties (Takahashi and Yamanaka, 2006). These transcription factors were known for being important in the long term maintenance of ES cell phenotype (Oct3/4 and Sox2) and pluripotency (c-myc and Klf4) (Takahashi and Yamanaka, 2006). These iPSCs are almost identical to ESCs in terms of their characteristics. They are able to differentiate into any cell type in the body, have infinite potential to grow, share the same morphology and have the same expression pattern of genes (Yamanaka, 2009); making them a potentially very powerful tool for complex disease research.

Primary microglia cultures are often used to study neuroinflammation, they can be derived from rat or mouse brain before birth or early on in development. In addition, human microglia cultures have also been established from fetal brain (McLarnon et al., 1997). One method of generating these cells was developed by Giulian and Baker (1986) and involving a specific process of adhesion and agitation. These cells are often used as they show similarities to microglial cells in vitro, however, the process of extraction and culture itself alters microglial phenotype (Caldeira et al., 2014). Given the degree of variability in ion channel distribution during development and aging (Harry, 2013), using this type of model for investigating neurodegeneration is less than ideal. Another method to study microglia is through the use of retroviral-immortalized cell lines, such as the mouse and rat microglial cell lines $\mathrm{N} 9$ and BV-2 respectively (Righi et al., 1989; Blasi et al., 1990). These cell lines offer an advantage in the fact that they are fast to grow, and large numbers of cells can be generated quickly. However, as they have been immortalized using oncogenes which means they differ from primary microglia as they have increased adhesion and proliferation and can vary in terms of their morphology (Horvath et al., 2008).

Until recently, being able to generate iPSC-derived microglia has been elusive, with previous attempts being met with skepticism as the microglia were made from induced hematopoietic stem cells (HSCs). HSCs have the potential to give rise to other cell types such as blood derived macrophages and as already stated microglia arise from EMPs. In order to generate EMPs from the iPSCs, Muffat and his colleagues developed a serum free media that contains high levels of IL-34 and colony stimulating factor 1 (CSF1) (Muffat and Li, 2016). These conditions were chosen as the media mimics the brain cerebrospinal fluid and the factors have been shown to be necessary for microglia differentiation and maintenance. Under these conditions they found that the cells soon formed rope-like structures that when plated onto low adherence plates gave rise to highly adherent pluripotent stem cell-derived microglia-like cells (pMGLs). These cells express many of the markers that would be expected from microglia, such as TMEM119, P2RY12/13, HEXB and GPR34. Alongside this they 
are also highly phagocytic and gene transcriptomic analysis demonstrated they resemble human primary fetal and adult microglia (Muffat and Li, 2016). This is not the only protocol that has been published which describes the derivation of microglia from iPSCs, subsequently there have been four more protocols released. In fact the next two papers described the generation of iPSC-derived microglia going through a hematopoietic progenitor cell (HPC) stage. Both methodologies use defined media systems that contain a number of growth factors including IL-3, BMP4 and L-ascorbic acid to generate HPCs (Abud et al., 2017; Pandya et al., 2017). Both protocols take about 10 days to generate HPCs at which point they were checked for markers of the hematopoietic lineage such as CD43 before differentiating for a further 2 weeks using another media to form induced microglia like cells (iMGLs). One way in which these protocols differ is that Pandya et al. (2017) co-culture the HPCs with astrocytes to enhance microglial differentiation. This is not the only protocol that uses co-culture to generate iPSC-derived microglia, a paper released by Walter Haenseler also uses co-culture but neuronal microglial co-culture instead (Haenseler et al., 2017).

Whilst iPSC-based models offer a number of advantages to modeling complex diseases there are a number of limitations that should also be considered. Firstly, the cells which are derived from iPSCs have been found to display the functional and epigenetic signatures of fetal neurons and do not maintain the features, such as telomere length and mitochondrial metabolism, of the cells from which they were originally derived (Lapasset et al., 2011). One of the current major stumbling blocks for iPSC research (control and those derived from patients with specific neurodegenerative disorders), is the lack of standard culturing or differentiation methods (Wen et al., 2016). Resulting in the unavailability of established protocols to generate entirely pure populations of a specific cell type, therefore making cross lab comparisons particularly difficult. However, more recently the availability of human tissue as well as iPSCs have provided new opportunities for academic and industry-based researchers to identify optimal cell types and culture conditions to efficiently generate stable, defined and reproducible cell types for their specific research-with limited variability. Whilst this may not be an issue for some studies, when trying to investigate diseases of aging such as AD it could pose more problems as cells may not show age related phenotypes or degeneration. One way in which it may be possible to overcome this is through maintain and aging the cells in culture for as long as possible.

One of the challenges to date has been modeling sporadic $\mathrm{AD}$ in both rodent and human models of disease, with familial AD mutations accounting for only $5-10 \%$ of all AD cases (Kim et al., 2017). Excitingly, Lin et al. (2018) describes the first experiments in which CRISPR/Cas9 technology has been used to generate isogenic APOE4 iPSC-derived microglia. In this study the APOE4-like microglia exhibited altered morphology correlating to the reduced $A \beta$ phagocytosis seen in rodent models. They found that consistently converting APOE4 to APOE3 in brain cell types from sporadic AD iPSCs was sufficient to diminish multiple AD-related pathologies (Lin et al., 2018).

TABLE 2 | Comparison of multiple transcriptome studies of regulated microglial genes, relating to ion channels, in models of aging or Alzheimer's disease.

\begin{tabular}{|c|c|c|c|c|c|c|c|}
\hline Species & $\begin{array}{l}\text { Sample } \\
\text { type }\end{array}$ & $\begin{array}{l}\text { Potassium } \\
\text { channels }\end{array}$ & $\begin{array}{l}\text { Sodium } \\
\text { channels }\end{array}$ & TRP channels & $\begin{array}{l}\text { Calcium } \\
\text { channels }\end{array}$ & Others & Reference \\
\hline Human & iPSC & $\begin{array}{l}\text { KCNA5, KCNK13, } \\
\text { KCNN4 }\end{array}$ & SCN5A & $\begin{array}{l}\text { TRPM2, TRPM4, TRPM8, } \\
\text { TRPV1, TRPV2 }\end{array}$ & CACNA1S & HVCN1, CLIC1 & $\begin{array}{l}\text { Haenseler et al., } \\
2017\end{array}$ \\
\hline Human & $\begin{array}{l}\text { Biopsy primary microglia } \\
\text { culture }\end{array}$ & $\begin{array}{l}\text { KCNK13, KCNN1, } \\
\text { KCNN4 }\end{array}$ & Not determined & $\begin{array}{l}\text { TRPC1, TRPC2, TRPM2, } \\
\text { TRPM3, TRPM4, TRPM7, } \\
\text { TRPMV1, TRPV2, TRPV4 }\end{array}$ & Not determined & HVCN1, CLIC1 & $\begin{array}{l}\text { Gosselin et al., } \\
2017\end{array}$ \\
\hline Human & $\begin{array}{l}\text { Purified from post-mortem } \\
\text { dorsal lateral pre-frontal } \\
\text { cortex }\end{array}$ & KCNN4 & Not determined & TRPM2, TRPV2 & Not determined & CLIC1 & Olah et al., 2018 \\
\hline Human & $\begin{array}{l}\text { Purified from post-mortem } \\
\text { dorsal lateral pre-frontal } \\
\text { cortex }\end{array}$ & $\begin{array}{l}\mathrm{KCNJ} 2, \mathrm{KCNK} 13 \\
\mathrm{KCNN} 4\end{array}$ & Not determined & $\begin{array}{l}\text { TRPM2, TRPM7, TRPV1, } \\
\text { TRPV2 }\end{array}$ & $\begin{array}{l}\text { CACNA1A, } \\
\text { CACNA1D }\end{array}$ & HVCN1, CLIC1 & Olah et al., 2018 \\
\hline Human & $\begin{array}{l}\text { Purified from post-mortem } \\
\text { right parietal cortex }\end{array}$ & KCNK13, KCNN4 & Not determined & TRPC2, TRPV2, TRPV4 & Not determined & CLIC1 & $\begin{array}{l}\text { Galatro et al., } \\
2017\end{array}$ \\
\hline Human & $\begin{array}{l}\text { Purified from post-mortem } \\
\text { right parietal cortex }\end{array}$ & KCNN4 & Not determined & Not determined & CACNA1F & Not determined & $\begin{array}{l}\text { Galatro et al., } \\
2017\end{array}$ \\
\hline Mouse & Primary microglia culture & $\begin{array}{l}\text { KCNA3, KCNK13, } \\
\text { KCNN4 }\end{array}$ & Not determined & TRPM4 & $\begin{array}{l}\text { CACNA1A, } \\
\text { CACNA1D }\end{array}$ & Not determined & $\begin{array}{l}\text { Gosselin et al., } \\
2017\end{array}$ \\
\hline Mouse & Collated Meta-Analysis & $\begin{array}{l}\text { KCNA1, KCNA2, } \\
\text { KCNN1, KCNN3 }\end{array}$ & Not determined & $\begin{array}{l}\text { TRPA1, TRPC1, TRPC3, } \\
\text { TRPC4, TRPC6, TRPC7, } \\
\text { TRPM3, TRPM8, TRPV1, } \\
\text { TRPV6 }\end{array}$ & Not determined & HVCN1 & Olah et al., 2018 \\
\hline Rat & Primary microglia culture & KCNK13, KCNN4 & Not determined & $\begin{array}{l}\text { TRPC4, TRPC6, TRPM2, } \\
\text { TRPM4, TRPV1 }\end{array}$ & Not determined & CLIC1 & Bohlen et al., 2017 \\
\hline
\end{tabular}

Regulation threshold was set at a 3-fold change over all studies. Anything below this is referred to as not determined. 
They also showed that in their iPSC-derived microglia, TREM2 was positively correlated to the APOE4 genotype. This data is consistent with reports showing increased levels of soluble TREM2 in cerebrospinal fluid of AD patients (Heslegrave et al., 2016). Similarly, protocols for microglia differentiated from patients carrying missense mutations in TREM2 (that are causal for frontotemporal dementia-like syndrome and Nasu-Hakola disease). These studies found subtle effects on microglia biology, consistent with the adult onset of disease in individuals with these mutations (Brownjohn et al., 2018). These particular studies establish a reference for human cell-type-specific changes associated with the risk of developing $\mathrm{AD}$, providing critical insight into potential treatments for sporadic AD.

As more is understood about the developmental origin and unique identity of microglia, recent studies have attempted to circumvent this issue by deriving microglia from iPSCs in order to study human and cell-type-specific biology and disease (Muffat et al., 2016; Abud et al., 2017; Douvaras et al., 2017; Haenseler et al., 2017; Pandya et al., 2017; Takata et al., 2017; Brownjohn et al., 2018; Lin et al., 2018). At the whole-transcriptome level, microglia generated by the methods reported here most closely resemble cultured primary microglia (Brownjohn et al., 2018). Due to a lack of unique surface markers, it has historically been difficult to distinguish microglia from other macrophages and cells of myeloid lineage. It is only recently that a distinct transcriptomic profile of microglia has emerged (Hickman et al., 2013; Butovsky et al., 2014; Holtman et al., 2015; Bennett et al., 2016; Gosselin et al., 2017; Keren-Shaul et al., 2017; Krasemann et al., 2017). In this review we have highlighted the similarities between rodent and human microglia transcriptomics and have identified key ion channels prominent in human iPSC-derived microglia, some of which we have already been highlighted earlier in this review as prominent targets associated with AD (Table 2) including KCNK13, KCNN4, TRPV2, HVCN1, and CLIC1. Indeed, the ion channels found from iPSC-derived microglia to date mirror those found in aged-human tissue (Olah et al., 2018).

Finally, the characterization of the electrophysiological properties of neurons derived from iPSCs are extremely limited and even fewer reports on the functional properties of iPSC-derived glia (microglia and astrocytes). However, with the development of standardized methods and differentiation protocols and, importantly, broader functional characterization of the complex collection of ion channels and receptors expressed

\section{REFERENCES}

Abud, E. M., Ramirez, R. N., Martinez, E. S., Healy, L. M., Nguyen, C. H.H., Newman, S. A., et al. (2017). iPSC-derived human microglialike cells to study neurological diseases. Neuron 94: 278-293.e9. doi: 10.1016/j.neuron.2017.03.042

Alexander, S. P., Kelly, E., Marrion, N. V., Peters, J. A., Faccenda, E., Harding, S. D., et al. (2017). The concise guide to pharmacology 2017/18: other ion channels. Br. J. Pharmacol. 174(Suppl. 1), S195-S207. doi: 10.1111/bph.13881

Alzheimer'sstatistics (2016). 2016 Alzheimer's Statistics. AvailableOnline at: http:// www.alzheimers.net/resources/alzheimers-statistics/ (Accessed December 13, 2016).

Annunziato, L., Boscia, F., and Pignataro, G. (2013). Ionic transporter activity in astrocytes, microglia, and oligodendrocytes during brain in defined glial and neuronal subtypes from iPSCs, their significance in drug discovery and neuroscience will become increasingly valuable.

\section{CONCLUDING REMARKS}

Microglial research has expanded dramatically in the last 5 years, this combined with the lack of new therapeutic options for treating complex neurological conditions highlights the potential of these cells to provide a viable alternative. For this to be realized a clearer picture of human microglial physiology needs to be established. The development of iPSC technology has been a great advance in these efforts, but robust protocols are still in their infancy (Douvaras et al., 2017; Haenseler et al., 2017; Brownjohn et al., 2018). With microglia being dependent in situ environments the need to generate more complex $3 \mathrm{D}$ models is even greater. While the development of 3D scaffolds continues at pace (Saliba et al., 2018), some initial research indicates the possibility of 3D microglia cultures (Cho et al., 2018). The challenge will now be to incorporate the diverse range of cells into these cultures with the ability to provided measurable outcomes (e.g. electrophysiology). Establishing robust and reproducible protocols will also allow us to progress into addressing the role of microglia in pathological states. This is vital if we are to achieve a therapeutic purpose for targeting microglia ion channels.

The role of ion channels is extensive within the central nervous system, however as non-excitable cells microglia channels often get overlooked. Here we have examined the microglia ion channel landscape and the evidence that supports the involvement in Alzheimer's disease pathogenesis. While there is still work to be done as highlighted above, this review indicates that microglia ion channels play a pivotal role in their physiology and can contribute to the fight against dementia.

\section{AUTHOR CONTRIBUTIONS}

TK and MD contributed to the initial design and conception of the review. LT, JI, EK, MD, and TK wrote individual sections of the review. TK wrote the first draft of the manuscript. LT and JI prepared figures. TK and LT outlined the tables and compiled final version of manuscript. All authors approved, read and revised final version before submission.

ischemia. J. Cereb. Blood Flow Metab. 33, 969-982. doi: 10.1038/jcbfm. 2013.44

Arnoux, I., Hoshiko, M., Mandavy, L., Avignone, E., Yamamoto, N., and Audinat, E. (2013). Adaptive phenotype of microglial cells during the normal postnatal development of the somatosensory "Barrel" cortex. Glia 61, 1582-1594. doi: 10.1002/glia.22503

Arnoux, I., Hoshiko, M., Sanz Diez, A., and Audinat, E. (2014). Paradoxical effects of minocycline in the developing mouse somatosensory cortex. Glia 62, 399-410. doi: 10.1002/glia.22612

Asai, H., Ikezu, S., Tsunoda, S., Medalla, M., Luebke, J., Haydar, T., et al. (2015). Depletion of microglia and inhibition of exosome synthesis halt tau propagation. Nat. Neurosci. 18, 1584-1593. doi: 10.1038/nn.4132

Atagi, Y., Liu, C. C., Painter, M. M., Chen, X. F., Verbeeck, C., Zheng, H., et al. (2015). Apolipoprotein E is a ligand for triggering receptor 
expressed on myeloid cells 2 (TREM2). J. Biol. Chem. 290, 26043-26050. doi: 10.1074/jbc.M115.679043

Beck, A., Penner, R., and Fleig, A. (2008). Lipopolysaccharide-induced downregulation of $\mathrm{Ca}^{2+}$ release-activated $\mathrm{Ca}^{2+}$ currents (I CRAC) but not $\mathrm{Ca}^{2+}$ activated TRPM4-like currents (I CAN) in cultured mouse microglial cells. J. Physiol. 586, 427-439. doi: 10.1113/jphysiol.2007.145151

Becker, K. J. (2016). Strain-related differences in the immune response: relevance to human stroke. Transl. Stroke. Res. 7, 303-312. doi: 10.1007/s12975-016-0455-9

Bellucci, A., Bugiani, O., Ghetti, B., and Spillantini, M. G. (2011). Presence of reactive microglia and neuroinflammatory mediators in a case of frontotemporal dementia with P301S mutation. Neurodegener. Dis. 8, 221-229. doi: $10.1159 / 000322228$

Bellucci, A., Westwood, A. J., Ingram, E., Casamenti, F., Goedert, M., and Spillantini, M. G. (2004). Induction of inflammatory mediators and microglial activation in mice transgenic for mutant human P301S tau protein. Am. J. Pathol. 165, 1643-1652. doi: 10.1016/S0002-9440(10)63421-9

Bennett, M. L., Bennett, F. C., Liddelow, S. A., Ajami, B., Zamanian, J. L., Fernhoff, N. B., et al. (2016). New tools for studying microglia in the mouse and human CNS. Proc. Natl. Acad. Sci. U. S. A. 113, E1738-E1746. doi: 10.1073/pnas.1525528113

Bertram, L., Lange, C., Mullin, K., Parkinson, M., Hsiao, M., Hogan, M. F., et al. (2008). Genome-wide association analysis reveals putative Alzheimer's disease susceptibility loci in addition to APOE. Am. J. Hum. Genet. 83, 623-632. doi: 10.1016/j.jhg.2008.10.008

Black, J. A., Liu, S., and Waxman, S. G. (2009). Sodium channel activity modulates multiple functions in microglia. Glia 57, 1072-1081. doi: 10.1002/glia.20830

Black, J. A., Newcombe, J., and Waxman, S. G., (2013). Nav1.5 sodium channels in macrophages in multiple sclerosis lesions. Mult. Scler. 19, 532-542. doi: $10.1177 / 1352458512460417$

Black, J. A., and Waxman, S. G. (2012). Sodium channels and microglial function. Exp. Neurol. 234, 302-315. doi: 10.1016/j.expneurol.2011.09.030

Blasi, E., Barluzzi, R., Bocchini, V., Mazzolla, R., and Bistoni, F. (1990). Immortalization of murine microglial cells by a $\mathrm{v}$-raf $/ \mathrm{v}$-myc carrying retrovirus. J. Neuroimmunol. 27, 229-237. doi: 10.1016/0165-5728(90)90073-V

Block, M. L., Zecca, L., and Hong, J. S. (2007). Microglia-mediated neurotoxicity: uncovering the molecular mechanisms. Nat. Rev. Neurosci. 8, 57-69. doi: $10.1038 / \mathrm{nrn} 2038$

Boche, D and Nicoll, J. A. (2010). Are we getting to grips with Alzheimer's disease at last? Brain 133, 1297-1299. doi: 10.1093/brain/awq099

Bohlen, C. J., Bennett, F. C., Tucker, A. F., Collins, H. Y., Mulinyawe, S. B., and Barres, B. A. (2017). Diverse requirements for microglial survival, specification, and function revealed by defined-medium cultures. Neuron 94, 759-773.e758. doi: 10.1016/j.neuron.2017.04.043

Bordey, A., and Spencer, D. D. (2003). Chemokine modulation of high-conductance $\mathrm{Ca}^{2+}$-sensitive $\mathrm{K}^{+}$currents in microglia from human hippocampi. Eur. J. Neurosci. 18, 2893-2898. doi: 10.1111/j.1460-9568.2003.03021.x

Bornemann, K. D., Wiederhold, K. H., Pauli, C., Ermini, F., Stalder, M., Schnell, L., et al. (2001). A $\beta$-Induced inflammatory processes in microglia cells of APP23 transgenic mice. Am. J. Pathol. 158, 63-73. doi: 10.1016/S0002-9440(10)63945-4

Boucsein, C., Kettenmann, H., and Nolte, C. (2000). Electrophysiological properties of microglial cells in normal and pathologic rat brain slices. Eur. J. Neurosci. 12, 2049-2058. doi: 10.1046/j.1460-9568.2000.00100.x

Boucsein, C., Zacharias, R., Farber, K., Pavlovic, S., Hanisch, U. K., and Kettenmann, H. (2003). Purinergic receptors on microglial cells: functional expression in acute brain slices and modulation of microglial activation in vitro. Eur. J. Neurosci. 17, 2267-2276. doi: 10.1046/j.1460-9568.2003.02663.x

Brackenbury, W. J., and Isom, L. L. (2008). Voltage-gated $\mathrm{Na}^{+}$channels: potential for beta subunits as therapeutic targets. Expert Opin. Ther. Targets 12, 1191-1203. doi: 10.1517/14728222.12.9.1191

Brackenbury, W. J., and Isom, L. L. (2011). Na channel beta subunits: overachievers of the ion channel family. Front. Pharmacol. 2:53. doi: 10.3389/fphar.2011.00053

Brownjohn, P. W., Smith, J., Solanki, R., Lohmann, E., Houlden, H., Hardy, J., et al. (2018). Functional studies of missense TREM2 mutations in human stem cell-derived microglia. Stem Cell Rep. 10, 1294-1307. doi: 10.1016/j.stemcr.2018.03.003
Burnstock, G. (2015). Physiopathological roles of P2X receptors in the central nervous system. Curr. Med. Chem. 22, 819-844. doi: 10.2174/0929867321666140706130415

Butovsky, O., Jedrychowski, M. P., Moore, C. S., Cialic, R., Lanser, A. J., Gabriely, G., et al. (2014). Identification of a unique TGF-beta-dependent molecular and functional signature in microglia. Nat. Neurosci. 17, 131-143. doi: 10.1038/nn.3599

Caldeira, C., Oliveira, A. F., Cunha, C., Vaz, A. R., Falcao, A. S., Fernandes, A., et al. (2014). Microglia change from a reactive to an age-like phenotype with the time in culture. Front. Cell Neurosci. 8:152. doi: 10.3389/fncel.2014.00152

Cameron, B., Tse, W., Lamb, R., Li, X., Lamb, B. T., and Landreth, G. E., (2012) Loss of interleukin receptor-associated kinase 4 signaling suppresses amyloid pathology and alters microglial phenotype in a mouse model of Alzheimer's disease. J. Neurosci. 32, 15112-15123. doi: 10.1523/JNEUROSCI.1729-12.2012

Capasso, M., Decoursey, T. E., and Dyer, M. J. (2011). pH regulation and beyond: unanticipated functions for the voltage-gated proton channel, HVCN1. Trends Cell Biol. 21, 20-28. doi: 10.1016/j.tcb.2010.09.006

Carrithers, L. M., Hulseberg, P., Sandor, M., and Carrithers, M. D. (2011). The human macrophage sodium channel NaV1.5 regulates mycobacteria processing through organelle polarization and localized calcium oscillations. FEMS Immunol. Med. Microbiol. 63, 319-327. doi: 10.1111/j.1574-695X.2011.00853.x

Carrithers, M. D., Chatterjee, G., Carrithers, L. M., Offoha, R., Iheagwara, U., Rahner, C., et al. (2009). Regulation of podosome formation in macrophages by a splice variant of the sodium channel SCN8A. J. Biol. Chem. 284, 8114-8126. doi: 10.1074/jbc.M801892200

Carrithers, M. D., Dib-Hajj, S., Carrithers, L. M., Tokmoulina, G., Pypaert, M., Jonas, E. A., et al. (2007). Expression of the voltage-gated sodium channel $\mathrm{NaV} 1.5$ in the macrophage late endosome regulates endosomal acidification. J. Immunol. 178, 7822-7832. doi: 10.4049/jimmunol.178.12.7822

Catterall, W. A., Goldin, A. L., and Waxman, S. G. (2005). International union of pharmacology. XLVII. Nomenclature and structure-function relationships of voltage-gated sodium channels. Pharmacol. Rev. 57, 397-409. doi: 10.1124/pr.57.4.4

Chakrabarty, P., Li, A., Ceballos-Diaz, C., Eddy, J. A., Funk, C. C., Moore, B., et al. (2015). IL-10 alters immunoproteostasis in APP mice, increasing plaque burden and worsening cognitive behavior. Neuron 85, 519-533. doi: 10.1016/j.neuron.2014.11.020

Cho, H. J., Verbridge, S. S., Davalos, R. V., and Lee, Y. W. (2018). Development of an in vitro 3D brain tissue model mimicking in vivo-like proinflammatory and pro-oxidative responses. Ann. Biomed. Eng. 46, 877-887. doi: 10.1007/s10439-018-2004-z

Chung, S., Jung, W., and Lee, M. Y. (1999). Inward and outward rectifying potassium currents set membrane potentials in activated rat microglia. Neurosci. Lett. 262, 121-124. doi: 10.1016/S0304-3940(99)00053-1

Chung, S., Lee, J., Joe, E. H., and Uhm, D. Y. (2001). Beta-amyloid peptide induces the expression of voltage dependent outward rectifying $\mathrm{K}^{+}$channels in rat microglia. Neurosci. Lett. 300, 67-70. doi: 10.1016/S0304-3940(01)01516-6

Colonna, M., and Wang, Y. (2016). TREM2 variants: new keys to decipher Alzheimer disease pathogenesis. Nat. Rev. Neurosci. 17, 201-207. doi: $10.1038 / \mathrm{nrn} .2016 .7$

Colton, C., and Wilcock, D. M. (2010). Assessing activation states in microglia. CNS Neurol. Disord. Drug Targets 9, 174-191. doi: $10.2174 / 187152710791012053$

Colton, C. A. (2009). Heterogeneity of microglial activation in the innate immune response in the brain. J. Neuroimmune. Pharmacol. 4, 399-418. doi: 10.1007/s11481-009-9164-4

Condello, C., Yuan, P., Schain, A., and Grutzendler, J. (2015). Microglia constitute a barrier that prevents neurotoxic protofibrillar Abeta42 hotspots around plaques. Nat. Commun. 6:6176: doi: 10.1038/ncomms7176

Cook, C., Kang, S. S., Carlomagno, Y., Lin, W. L., Yue, M., Kurti, A., et al. (2015). Tau deposition drives neuropathological, inflammatory and behavioral abnormalities independently of neuronal loss in a novel mouse model. Hum. Mol. Genet. 24, 6198-6212. doi: 10.1093/hmg/ddv336

Coraci, I. S., Husemann, J., Berman, J. W., Hulette, C., Dufour, J. H., Campanella, G. K., et al. (2002). CD36, a class B scavenger receptor, is expressed on microglia in Alzheimer's disease brains and can mediate production of reactive oxygen species in response to beta-amyloid fibrils. Am. J. Pathol. 160, 101-112. doi: $10.1016 / S 0002-9440(10) 64354-4$ 
Corder, E. H., Saunders, A. M., Strittmatter, W. J., Schmechel, D. E., Gaskell, P. C., Small, G. W., et al. (1993). Gene dose of apolipoprotein E type 4 allele and the risk of Alzheimer's disease in late onset families. Science 261, 921-923. doi: $10.1126 /$ science. 8346443

Craner, M. J., Damarjian, T. G., Liu, S., Hains, B. C., Lo, A. C., Black, J. A., et al. (2005). Sodium channels contribute to microglia/macrophage activation and function in EAE and MS. Glia 49, 220-229. doi: 10.1002/glia.20112

De Simoni, A., Allen, N. J., and Attwell, D. (2008). Charge compensation for NADPH oxidase activity in microglia in rat brain slices does not involve a proton current. Eur. J. Neurosci. 28, 1146-1156. doi: 10.1111/j.1460-9568.2008.06417.x

DeCoursey, T. E. (2008). Voltage-gated proton channels. Cell Mol. Life Sci. 65, 2554-2573. doi: 10.1007/s00018-008-8056-8

Douvaras, P., Sun, B., Wang, M., Kruglikov, I., Lallos, G., Zimmer, M., et al. (2017). Directed differentiation of human pluripotent stem cells to microglia. Stem Cell Rep. 8, 1516-1524. doi: 10.1016/j.stemcr.2017.04.023

Draheim, H. J., Prinz, M., Weber, J. R., Weiser, T., Kettenmann, H., and Hanisch, U. K. (1999). Induction of potassium channels in mouse brain microglia: cells acquire responsiveness to pneumococcal cell wall components during late development. Neuroscience 89, 1379-1390. doi: 10.1016/S0306-4522(98)00407-2

Eder, C. (1998). Ion channels in microglia (brain macrophages). Am. J. Physiol. 275, C327-C342. doi: 10.1152/ajpcell.1998.275.2.C327

Eder, C. (2005). Regulation of microglial behavior by ion channel activity. $J$. Neurosci. Res. 81, 314-321. doi: 10.1002/jnr.20476

Eder, C. (2010). Ion channels in monocytes and microglia/brain macrophages: promising therapeutic targets for neurological diseases. J. Neuroimmunol. 224, 51-55. doi: 10.1016/j.jneuroim.2010.05.008

Eder, C., and Decoursey, T. E. (2001). Voltage-gated proton channels in microglia. Prog. Neurobiol. 64, 277-305. doi: 10.1016/S0301-0082(00)00062-9

Eder, C., Fischer, H. G., Hadding, U., and Heinemann, U. (1995). Properties of voltage-gated currents of microglia developed using macrophage colony-stimulating factor. Pflugers Arch. 430, 526-533. doi: 10.1007/BF003 73889

Eder, C., and Heinemann, U. (1996). Proton modulation of outward $\mathrm{K}^{+}$currents in interferon-gamma-activated microglia. Neurosci. Lett. 206, 101-104. doi: 10.1016/S0304-3940(96)12433-2

Eder, C., Schilling, T., Heinemann, U., Haas, D., Hailer, N., and Nitsch, R. (1999). Morphological, immunophenotypical and electrophysiological properties of resting microglia in vitro. Eur. J. Neurosci. 11, 4251-4261. doi: 10.1046/j.1460-9568.1999.00852.x

Ertel, E. A., Campbell, K. P., Harpold, M. M., Hofmann, F., Mori, Y., Perez-Reyes, E., et al. (2000). Nomenclature of voltage-gated calcium channels. Neuron 25, 533-535. doi: 10.1016/S0896-6273(00)81057-0

Espinosa-Parrilla, J. F., Martinez-Moreno, M., Gasull, X., Mahy, N., and Rodriguez, M. J. (2015). The L-type voltage-gated calcium channel modulates microglial pro-inflammatory activity. Mol. Cell. Neurosci. 64, 104-115. doi: 10.1016/j.men.2014.12.004

Evans, M. J., and Kaufman, M. H. (1981). Establishment in culture of pluripotential cells from mouse embryos. Nature 292, 154-156. doi: 10.1038/292154a0

Fischer, H. G., Eder, C., Hadding, U., and Heinemann, U. (1995). Cytokine-dependent $\mathrm{K}^{+}$channel profile of microglia at immunologically defined functional states. Neuroscience 64, 183-191. doi: 10.1016/0306-4522(94)00398-O

Fordyce, C. B., Jagasia, R., Zhu, X., and Schlichter, L. C. (2005). Microglia Kv1.3 channels contribute to their ability to kill neurons. J. Neurosci. 25, 7139-7149. doi: 10.1523/JNEUROSCI.1251-05.2005

Franchini, L., Levi, G., and Visentin, S. (2004). Inwardly rectifying $\mathrm{K}^{+}$channels influence $\mathrm{Ca}^{2+}$ entry due to nucleotide receptor activation in microglia. Cell Calcium 35, 449-459. doi: 10.1016/j.ceca.2003.11.001

Franciosi, S., Ryu, J. K., Choi, H. B., Radov, L., Kim, S. U., and Mclarnon, J. G. (2006). Broad-spectrum effects of 4-aminopyridine to modulate amyloid beta1-42-induced cell signaling and functional responses in human microglia. J. Neurosci. 26, 11652-11664. doi: 10.1523/JNEUROSCI.2490-06.2006

Galatro, T. F., Holtman, I. R., Lerario, A. M., Vainchtein, I. D., Brouwer, N., Sola, P. R., et al. (2017). Transcriptomic analysis of purified human cortical microglia reveals age-associated changes. Nat. Neurosci. 20:1162. doi: 10.1038/ nn. 4597
Ganter, S., Northoff, H., Mannel, D., and Gebicke-Harter, P. J. (1992). Growth control of cultured microglia. J. Neurosci. Res. 33, 218-230. doi: 10.1002/jnr.490330205

Garcia-Calvo, M., Leonard, R. J., Novick, J., Stevens, S. P., Schmalhofer, W., Kaczorowski, G. J., et al. (1993). Purification, characterization, and biosynthesis of margatoxin, a component of Centruroides margaritatus venom that selectively inhibits voltage-dependent potassium channels. J. Biol. Chem. 268, 18866-18874.

Gatz, M., Reynolds, C. A., Fratiglioni, L., Johansson, B., Mortimer, J. A., Berg, S., et al. (2006). Role of genes and environments for explaining Alzheimer disease. Arch. Gen. Psychiatr. 63, 168-174. doi: 10.1001/archpsyc.63.2.168

Ginhoux, F., Greter, M., Leboeuf, M., Nandi, S., See, P., Gokhan, S., et al. (2010). Fate mapping analysis reveals that adult microglia derive from primitive macrophages. Science 330, 841-845. doi: 10.1126/science.1194637

Giulian, D., and Baker, T. J. (1986). Characterization of ameboid microglia isolated from developing mammalian brain. J. Neurosci. 6, 2163-2178. doi: 10.1523/JNEUROSCI.06-08-02163.1986

Gosselin, D., Skola, D., Coufal, N. G., Holtman, I. R., Schlachetzki, J. C.M., Sajti, E., et al. (2017). An environment-dependent transcriptional network specifies human microglia identity. Science 356:eaal3222. doi: 10.1126/science.aal3222

Grathwohl, S. A., Kalin, R. E., Bolmont, T., Prokop, S., Winkelmann, G., Kaeser, S. A., et al. (2009). Formation and maintenance of Alzheimer's disease betaamyloid plaques in the absence of microglia. Nat. Neurosci. 12, 1361-1363. doi: $10.1038 / \mathrm{nn} .2432$

Guerreiro, R., Wojtas, A., Bras, J., Carrasquillo, M., Rogaeva, E., Majounie, E., et al. (2013). TREM2 variants in Alzheimer's disease. N. Engl. J. Med. 368, 117-127. doi: 10.1056/NEJMoa1211851

Guillot-Sestier, M. V., Doty, K. R., Gate, D., Rodriguez, J. Jr., Leung, B. P., Rezai-Zadeh, K., et al. (2015). Il10 deficiency rebalances innate immunity to mitigate Alzheimer-like pathology. Neuron 85, 534-548. doi: 10.1016/j.neuron.2014.12.068

Haenseler, W., Sansom, S. N., Buchrieser, J., Newey, S. E., Moore, C. S. Nicholls, F. J., et al. (2017). A highly efficient human pluripotent stem cell microglia model displays a neuronal-co-culture-specific expression profile and inflammatory response. Stem Cell Rep. 8, 1727-1742. doi: 10.1016/j.stemcr.2017.05.017

Harold, D., Abraham, R., Hollingworth, P., Sims, R., Gerrish, A., Hamshere, M. L., et al. (2009). Genome-wide association study identifies variants at CLU and PICALM associated with Alzheimer's disease. Nat. Genet. 41, 1088-1093. doi: $10.1038 /$ ng.440

Harry, G. J. (2013). Microglia during development and aging. Pharmacol. Ther. 139, 313-326. doi: 10.1016/j.pharmthera.2013.04.013

Harteneck, C. (2005). Function and pharmacology of TRPM cation channels. Naunyn Schmiedebergs Arch. Pharmacol. 371, 307-314. doi: 10.1007/s00210-005-1034-x

Hashioka, S., Klegeris, A., and Mcgeer, P. L. (2012). Inhibition of human astrocyte and microglia neurotoxicity by calcium channel blockers. Neuropharmacology 63, 685-691. doi: 10.1016/j.neuropharm.2012.05.033

Heneka, M. T., Carson, M. J., El Khoury, J., Landreth, G. E., Brosseron, F., Feinstein, D. L., et al. (2015). Neuroinflammation in Alzheimer's disease. Lancet Neurol. 14, 388-405. doi: 10.1016/S1474-4422(15)70016-5

Heneka, M. T., Kummer, M. P., Stutz, A., Delekate, A., Schwartz, S., Vieira-Saecker, A., et al. (2013). NLRP3 is activated in Alzheimer's disease and contributes to pathology in APP/PS1 mice. Nature 493, 674-678. doi: 10.1038/nature11729

Heneka, M. T., Sastre, M., Dumitrescu-Ozimek, L., Dewachter, I., Walter, J., Klockgether, T., et al. (2005). Focal glial activation coincides with increased BACE1 activation and precedes amyloid plaque deposition in APP[V717I] transgenic mice. J. Neuroinflammation. 2:22. doi: 10.1186/1742-2094-2-22

Heslegrave, A., Heywood, W., Paterson, R., Magdalinou, N., Svensson, J., Johansson, P., et al. (2016). Increased cerebrospinal fluid soluble TREM2 concentration in Alzheimer's disease. Mol. Neurodegener. 11:3. doi: 10.1186/s13024-016-0071-x

Hickman, S. E., Allison, E. K., and El Khoury, J. (2008). Microglial dysfunction and defective beta-amyloid clearance pathways in aging Alzheimer's disease mice. J. Neurosci. 28, 8354-8360. doi: 10.1523/JNEUROSCI.0616-08.2008

Hickman, S. E., and El Khoury, J. (2013). The neuroimmune system in Alzheimer's disease: the glass is half full. J. Alzheimers Dis. 33(Suppl. 1), S295-302. doi: 10.3233/JAD-2012-129027 
Hickman, S. E., Kingery, N. D., Ohsumi, T. K., Borowsky, M. L., Wang, L. C., Means, T. K., et al. (2013). The microglial sensome revealed by direct RNA sequencing. Nat. Neurosci. 16, 1896-1905. doi: 10.1038/nn.3554

Hines, D. J., Hines, R. M., Mulligan, S. J., and Macvicar, B. A. (2009). Microglia processes block the spread of damage in the brain and require functional chloride channels. Glia 57, 1610-1618. doi: 10.1002/glia.20874

Hollingworth, P., Harold, D., Sims, R., Gerrish, A., Lambert, J. C., Carrasquillo, M. M., et al. (2011). Common variants at ABCA7, MS4A6A/MS4A4E, EPHA1, CD33 and CD2AP are associated with Alzheimer's disease. Nat. Genet. 43, 429-435. doi: 10.1038/ng.803

Holtman, I. R., Raj, D. D., Miller, J. A., Schaafsma, W., Yin, Z., Brouwer, N., et al. (2015). Induction of a common microglia gene expression signature by aging and neurodegenerative conditions: a co-expression meta-analysis. Acta Neuropathol. Commun. 3:31. doi: 10.1186/s40478-015-0203-5

Horvath, R. J., Nutile-Mcmenemy, N., Alkaitis, M. S., and Deleo, J. A. (2008). Differential migration, LPS-induced cytokine, chemokine, and NO expression in immortalized BV-2 and HAPI cell lines and primary microglial cultures. J. Neurochem. 107, 557-569. doi: 10.1111/j.1471-4159.2008.05633.x

Hsieh, C. L., Koike, M., Spusta, S. C., Niemi, E. C., Yenari, M., Nakamura, M. C., et al. (2009). A role for TREM2 ligands in the phagocytosis of apoptotic neuronal cells by microglia. J. Neurochem. 109, 1144-1156. doi: 10.1111/j.1471-4159.2009.06042.x

Huang, S., Turlova, E., Li, F., Bao, M.-H., Szeto, V., Wong, R., et al. (2017). Transient receptor potential melastatin 2 channels (TRPM2) mediate neonatal hypoxic-ischemic brain injury in mice. Exp. Neurol. 296, 32-40. doi: 10.1016/j.expneurol.2017.06.023

Huang, Y. (2010). A beta-independent roles of apolipoprotein E4 in the pathogenesis of Alzheimer's disease. Trends Mol. Med. 16, 287-294. doi: 10.1016/j.molmed.2010.04.004

Hutchins, K. D., Dickson, D. W., Rashbaum, W. K., and Lyman, W. D. (1990). Localization of morphologically distinct microglial populations in the developing human fetal brain: implications for ontogeny. Brain Res. Dev. Brain Res. 55, 95-102. doi: 10.1016/0165-3806(90)90109-C

Ikeda, M., Shoji, M., Kawarai, T., Kawarabayashi, T., Matsubara, E., Murakami, T., et al. (2005). Accumulation of filamentous tau in the cerebral cortex of human tau R406W transgenic mice. Am. J. Pathol. 166, 521-531. doi: $10.1016 / S 0002-9440(10) 62274-2$

Janelsins, M. C., Mastrangelo, M. A., Oddo, S., Laferla, F. M., Federoff, H. J., and Bowers, W. J. (2005). Early correlation of microglial activation with enhanced tumor necrosis factor-alpha and monocyte chemoattractant protein-1 expression specifically within the entorhinal cortex of triple transgenic Alzheimer's disease mice. J. Neuroinflammation 2:23. doi: 10.1186/1742-2094-2-23

Jay, T. R., Hirsch, A. M., Broihier, M. L., Miller, C. M., Neilson, L. E., Ransohoff, R. M., et al. (2017). Disease progression-dependent effects of TREM2 deficiency in a mouse model of Alzheimer's Disease. J. Neurosci. 37, 637-647. doi: 10.1523/JNEUROSCI.2110-16.2016

Jay, T. R., Miller, C. M., Cheng, P. J., Graham, L. C., Bemiller, S., Broihier, M. L., et al. (2015). TREM2 deficiency eliminates TREM $^{2+}$ inflammatory macrophages and ameliorates pathology in Alzheimer's disease mouse models. J. Exp. Med. 212, 287-295. doi: 10.1084/jem.20142322

Jeong, H., Kim, Y. H., Lee, Y., Jung, S. J., and Oh, S. B. (2017). TRPM2 contributes to LPC-induced intracellular $\mathrm{Ca}^{2+}$ influx and microglial activation. Biochem. Biophys. Res. Commun. 485, 301-306. doi: 10.1016/j.bbrc.2017.02.087

Jiang, X., Newell, E. W., and Schlichter, L. C. (2003). Regulation of a TRPM7like current in rat brain microglia. J. Biol. Chem. 278, 42867-42876. doi: $10.1074 /$ jbc.M304487200

Jiang, Y., Lee, A., Chen, J., Ruta, V., Cadene, M., Chait, B. T., et al. (2003). $\mathrm{X}$-ray structure of a voltage-dependent $\mathrm{K}^{+}$channel. Nature 423, 33-41. doi: 10.1038/nature01580

Jin, S. C., Benitez, B. A., Karch, C. M., Cooper, B., Skorupa, T., Carrell, D., et al. (2014). Coding variants in TREM2 increase risk for Alzheimer's disease. Hum. Mol. Genet. 23, 5838-5846. doi: 10.1093/hmg/ddu277

Johansson, J. U., Woodling, N. S., Brown, H. D., Wang, Q., and Andreasson, K. I. (2015). Microarray analysis of the in vivo response of microglia to Abeta peptides in mice with conditional deletion of the prostaglandin EP2 receptor. Genom. Data 5, 268-271. doi: 10.1016/j.gdata.2015.06.011
Jonsson, T., Stefansson, H., Steinberg, S., Jonsdottir, I., Jonsson, P. V., Snaedal, J., et al. (2013). Variant of TREM2 associated with the risk of Alzheimer's disease. N. Engl. J. Med. 368, 107-116. doi: 10.1056/NEJMoa1211103

Jou, I., Pyo, H., Chung, S., Jung, S. Y., Gwag, B. J., and Joe, E. H. (1998). Expression of Kv1.5 $\mathrm{K}^{+}$channels in activated microglia in vivo. Glia 24, 408-414.

Kaushal, V., Koeberle, P. D., Wang, Y., and Schlichter, L. C. (2007). The $\mathrm{Ca}^{2+}$ activated $\mathrm{K}^{+}$channel $\mathrm{KCNN} 4 / \mathrm{KCa} 3.1$ contributes to microglia activation and nitric oxide-dependent neurodegeneration. J. Neurosci. 27, 234-244. doi: 10.1523/JNEUROSCI.3593-06.2007

Keren-Shaul, H., Spinrad, A., Weiner, A., Matcovitch-Natan, O., Dvir-Szternfeld, R., Ulland, T. K., et al. (2017). A unique microglia type associated with restricting development of Alzheimer's disease. Cell 169, 1276-1290 e1217. doi: 10.1016/j.cell.2017.05.018

Kettenmann, H., Banati, R., and Walz, W. (1993). Electrophysiological behavior of microglia. Glia 7, 93-101. doi: 10.1002/glia.440070115

Kettenmann, H., Hanisch, U. K., Noda, M., and Verkhratsky, A. (2011). Physiology of microglia. Physiol. Rev. 91, 461-553. doi: 10.1152/physrev.00011.2010

Kettenmann, H., Hoppe, D., Gottmann, K., Banati, R., and Kreutzberg, G. (1990). Cultured microglial cells have a distinct pattern of membrane channels different from peritoneal macrophages. J. Neurosci. Res. 26, 278-287. doi: $10.1002 /$ jnr. 490260303

Khanna, R., Roy, L., Zhu, X., and Schlichter, L. C. (2001). K ${ }^{+}$channels and the microglial respiratory burst. Am. J. Physiol. Cell Physiol. 280, C796-806. doi: 10.1152/ajpcell.2001.280.4.C796

Kim, H., Yoo, J., Shin, J., Chang, Y., Jung, J., Jo, D.-G., et al. (2017). Modelling APOE $\varepsilon 3 / 4$ allele-associated sporadic Alzheimer's disease in an induced neuron. Brain 140, 2193-2209. doi: 10.1093/brain/awx144

Kim, S. R., Kim, S. U., Oh, U., and Jin, B. K. (2006). Transient receptor potential vanilloid subtype 1 mediates microglial cell death in vivo and in vitro via $\mathrm{Ca}^{2+}$. mediated mitochondrial damage and cytochrome c release. J. Immunol. 177, 4322-4329. doi: 10.4049/jimmunol.177.7.4322

Kis-Toth, K., Hajdu, P., Bacskai, I., Szilagyi, O., Papp, F., Szanto, A., et al. (2011). Voltage-gated sodium channel Nav1.7 maintains the membrane potential and regulates the activation and chemokine-induced migration of a monocyte-derived dendritic cell subset. J. Immunol. 187, 1273-1280. doi: 10.4049/jimmunol.1003345

Kitazawa, M., Oddo, S., Yamasaki, T. R., Green, K. N., and Laferla, F. M. (2005). Lipopolysaccharide-induced inflammation exacerbates tau pathology by a cyclin-dependent kinase 5-mediated pathway in a transgenic model of Alzheimer's disease. J. Neurosci. 25, 8843-8853. doi: 10.1523/JNEUROSCI.2868-05.2005

Klee, R., Heinemann, U., and Eder, C. (1998). Changes in proton currents in murine microglia induced by cytoskeletal disruptive agents. Neurosci. Lett. 247, 191-194. doi: 10.1016/S0304-3940(98)00322-X

Klee, R., Heinemann, U., and Eder, C. (1999). Voltage-gated proton currents in microglia of distinct morphology and functional state. Neuroscience 91, 1415-1424. doi: 10.1016/S0306-4522(98)00710-6

Kleinberger, G., Yamanishi, Y., Suarez-Calvet, M., Czirr, E., Lohmann, E., Cuyvers, E., et al. (2014). TREM2 mutations implicated in neurodegeneration impair cell surface transport and phagocytosis. Sci. Transl. Med. 6:243ra286. doi: 10.1126/scitranslmed.3009093

Koenigsknecht-Talboo, J., Meyer-Luehmann, M., Parsadanian, M., Garcia-Alloza, M., Finn, M. B., Hyman, B. T., et al. (2008). Rapid microglial response around amyloid pathology after systemic anti-Abeta antibody administration in PDAPP mice. J. Neurosci. 28, 14156-14164. doi: 10.1523/JNEUROSCI.4147-08.2008

Korotzer, A. R., and Cotman, C. W. (1992). Voltage-gated currents expressed by rat microglia in culture. Glia 6, 81-88. doi: 10.1002/glia.440060202

Korotzer, A. R., Whittemore, E. R., and Cotman, C. W. (1995). Differential regulation by beta-amyloid peptides of intracellular free $\mathrm{Ca}^{2+}$ concentration in cultured rat microglia. Eur. J. Pharmacol. 288, 125-130. doi: 10.1016/0922-4106(95)90006-3

Kotecha, S. A., and Schlichter, L. C. (1999). A Kv1.5 to Kv1.3 switch in endogenous hippocampal microglia and a role in proliferation. J. Neurosci. 19, 10680-10693. doi: 10.1523/JNEUROSCI.19-24-10680.1999

Krabbe, G., Halle, A., Matyash, V., Rinnenthal, J. L., Eom, G. D., Bernhardt, U., et al. (2013). Functional impairment of microglia coincides with beta-amyloid 
deposition in mice with Alzheimer-like pathology. PLoS ONE 8:e60921. doi: 10.1371/journal.pone.0060921

Kraft, R. (2015). STIM and ORAI proteins in the nervous system. Channels 9, 244-252. doi: 10.1080/19336950.2015.1071747

Krasemann, S., Madore, C., Cialic, R., Baufeld, C., Calcagno, N., El Fatimy, R., et al. (2017). The TREM2-APOE pathway drives the transcriptional phenotype of dysfunctional microglia in neurodegenerative diseases. Immunity 47, 566-581 e569. doi: 10.1016/j.immuni.2017.08.008

Kuang, Q., Purhonen, P., and Hebert, H. (2015). Structure of potassium channels. Cell Mol. Life Sci. 72, 3677-3693. doi: 10.1007/s00018-015-1948-5

Kurland, D. B., Gerzanich, V., Karimy, J. K., Woo, S. K., Vennekens, R., Freichel, M., et al. (2016). The Sur1-Trpm4 channel regulates NOS2 transcription in TLR4-activated microglia. J. Neuroinflammation 13:130. doi: 10.1186/s12974-016-0599-2

Lam, D., Lively, S., and Schlichter, L. C., (2017). Responses of rat and mouse primary microglia to pro- and anti-inflammatory stimuli: molecular profiles, $\mathrm{K}(+)$ channels and migration. J. Neuroinflammation 14:166. doi: 10.1186/s12974-017-0941-3

Lambert, J. C., Ibrahim-Verbaas, C. A., Harold, D., Naj, A. C., Sims, R., Bellenguez, C., et al. (2013). Meta-analysis of 74,046 individuals identifies 11 new susceptibility loci for Alzheimer's disease. Nat. Genet. 45, 1452-1458. doi: $10.1038 /$ ng. 2802

Lapasset, L., Milhavet, O., Prieur, A., Besnard, E., Babled, A., Ait-Hamou, N., et al. (2011). Rejuvenating senescent and centenarian human cells by reprogramming through the pluripotent state. Genes Dev. 25, 2248-2253. doi: $10.1101 /$ gad.173922.111

Lawson, L. J., Perry, V. H., Dri, P., and Gordon, S. (1990). Heterogeneity in the distribution and morphology of microglia in the normal adult-mouse brain. Neuroscience 39, 151-170. doi: 10.1016/0306-4522(90)90229-W

Lee, C. Y., and Landreth, G. E. (2010). The role of microglia in amyloid clearance from the AD brain. J. Neural. Transm (Vienna) 117, 949-960. doi: 10.1007/s00702-010-0433-4

Lewis, R. S., Ross, P. E., and Cahalan, M. D. (1993). Chloride channels activated by osmotic stress in T lymphocytes. J. Gen. Physiol. 101, 801-826. doi: 10.1085/jgp.101.6.801

Li, F., Zhu, S., Wu, C., Yan, C., Liu, Y., and Shugan, L. (2011). Neuroinflammation and cell therapy for Parkinson's disease. Front. Biosci (Schol Ed) 3, 1407-1420. doi: $10.2741 / 232$

Li, J. T., and Zhang, Y. (2018). TREM2 regulates innate immunity in Alzheimer's disease. J. Neuroinflammation 15:107. doi: 10.1186/s12974-018-1148-y

Li, R., Huang, Y. G., Fang, D., and Le, W. D. (2004). (-)-Epigallocatechin gallate inhibits lipopolysaccharide-induced microglial activation and protects against inflammation-mediated dopaminergic neuronal injury. J. Neurosci. Res. 78, 723-731. doi: 10.1002/jnr.20315

Lim, J.-E., Kou, J., Song, M., Pattanayak, A., Jin, J., Lalonde, R., et al. (2011). MyD88 deficiency ameliorates $\beta$-Amyloidosis in an animal model of alzheimer's disease. Am. J. Pathol. 179, 1095-1103. doi: 10.1016/j.ajpath.2011.05.045

Lim, J. E., Song, M., Jin, J., Kou, J., Pattanayak, A., Lalonde, R., et al. (2012). The effects of MyD88 deficiency on exploratory activity, anxiety, motor coordination, and spatial learning in C57BL/6 and APPswe/PS1dE9 mice. Behav. Brain Res. 227, 36-42. doi: 10.1016/j.bbr.2011. 10.027

Lin, Y. T., Seo, J., Gao, F., Feldman, H. M., Wen, H. L., Penney, J., et al. (2018). APOE4 causes widespread molecular and cellular alterations associated with alzheimer's disease phenotypes in human iPSC-derived brain cell types. Neuron. 98, 1141-1154.e7. doi: 10.1016/j.neuron.2018.05.008

Lioudyno, M. I., Broccio, M., Sokolov, Y., Rasool, S., Wu, J., Alkire, M. T., et al. (2012). Effect of synthetic abeta peptide oligomers and fluorinated solvents on Kv1.3 channel properties and membrane conductance. PLOS ONE 7:e35090. doi: 10.1371/journal.pone.0035090

Liu, N., Zhuang, Y., Zhou, Z., Zhao, J., Chen, Q., and Zheng, J. (2017). NF-kappaB dependent up-regulation of TRPC6 by Abeta in BV-2 microglia cells increases COX-2 expression and contributes to hippocampus neuron damage. Neurosci. Lett. 651, 1-8. doi: 10.1016/j.neulet.2017.04.056

Long, S. B., Campbell, E. B., and Mackinnon, R. (2005). Crystal structure of a mammalian voltage-dependent Shaker family $\mathrm{K}^{+}$channel. Science 309, 897-903. doi: 10.1126/science.1116269
Long, S. B., Tao, X., Campbell, E. B., and Mackinnon, R. (2007). Atomic structure of a voltage-dependent $\mathrm{K}^{+}$channel in a lipid membrane-like environment. Nature 450, 376-382. doi: 10.1038/nature06265

Madry, C., Kyrargyri, V., Arancibia-Carcamo, I. L., Jolivet, R., Kohsaka, S., Bryan, R. M., et al. (2018). Microglial ramification, surveillance, and interleukin- $1 \beta$ release are regulated by the two-pore domain $\mathrm{K}^{+}$channel THIK-1. Neuron 97 , 299.e6-312.e6 e296. doi: 10.1016/j.neuron.2017.12.002

Maezawa, I., Jenkins, D. P., Jin, B. E., and Wulff, H. (2012). Microglial KCa3.1 channels as a potential therapeutic target for Alzheimer's disease. Int. J. Alzheimers Dis. 2012:868972. doi: 10.1155/2012/868972

Maezawa, I., Nguyen, H. M., Di Lucente, J., Jenkins, D. P., Singh, V., Hilt, S., et al. (2017). Kv1.3 inhibition as a potential microglia-targeted therapy for Alzheimer's disease: preclinical proof of concept. Brain. 141, 596-612. doi: 10.1093/brain/awx346

Maezawa, I., Zimin, P. I., Wulff, H., and Jin, L. W. (2011). Amyloidbeta protein oligomer at low nanomolar concentrations activates microglia and induces microglial neurotoxicity. J. Biol. Chem. 286, 3693-3706. doi: 10.1074/jbc.M110.135244

McGowan, E., Eriksen, J., and Hutton, M. (2006). A decade of modeling Alzheimer's disease in transgenic mice. Trends Genet. 22, 281-289. doi: 10.1016/j.tig.2006.03.007

McLarnon, J. G., Franciosi, S., Wang, X., Bae, J. H., Choi, H. B., and Kim, S. U. (2001). Acute actions of tumor necrosis factor-alpha on intracellular $\mathrm{Ca}(2+)$ and $\mathrm{K}(+)$ currents in human microglia. Neuroscience 104, 1175-1184. doi: 10.1016/S0306-4522(01)00119-1

McLarnon, J. G., Sawyer, D., and Kim, S. U. (1995). Cation and anion unitary ion channel currents in cultured bovine microglia. Brain Res. 693, 8-20. doi: 10.1016/0006-8993(95)00664-C

McLarnon, J. G., Xu, R., Lee, Y. B., and Kim, S. U. (1997). Ion channels of human microglia in culture. Neuroscience 78, 1217-1228. doi: 10.1016/S0306-4522(96)00680-X

McLarnon, J. G., Zhang, L., Goghari, V., Lee, Y. B., Walz, W., Krieger, C., et al. (1999). Effects of ATP and elevated $\mathrm{K}^{+}$on $\mathrm{K}^{+}$currents and intracellular $\mathrm{Ca}^{2+}$ in human microglia. Neuroscience 91, 343-352. doi: 10.1016/S0306-4522(98)00491-6

Menteyne, A., Levavasseur, F., Audinat, E., and Avignone, E. (2009). Predominant functional expression of Kv1.3 by activated microglia of the hippocampus after Status epilepticus. PLoS ONE 4:e6770. doi: 10.1371/journal.pone.0006770

Meotti, F. C., Figueiredo, C. P., Manjavachi, M., and Calixto, J. B. (2017). The transient receptor potential ankyrin-1 mediates mechanical hyperalgesia induced by the activation of B1 receptor in mice. Biochem. Pharmacol. 125, 75-83. doi: 10.1016/j.bcp.2016.11.003

Meyer-Luehmann, M., Spires-Jones, T. L., Prada, C., Garcia-Alloza, M., De Calignon, A., Rozkalne, A., et al. (2008). Rapid appearance and local toxicity of amyloid-[bgr] plaques in a mouse model of Alzheimer/'s disease. Nature 451, 720-724. doi: 10.1038/nature06616

Milton, R. H., Abeti, R., Averaimo, S., Debiasi, S., Vitellaro, L., Jiang, L., et al. (2008). CLIC1 function is required for beta-amyloid-induced generation of reactive oxygen species by microglia. J. Neurosci. 28, 11488-11499. doi: 10.1523/JNEUROSCI.2431-08.2008

Miyake, T., Shirakawa, H., Kusano, A., Sakimoto, S., Konno, M., Nakagawa, T., et al. (2014). TRPM2 contributes to LPS/IFN $\gamma$-induced production of nitric oxide via the p38/JNK pathway in microglia. Biochem. Biophys. Res. Commun. 444, 212-217. doi: 10.1016/j.bbrc.2014.01.022

Miyake, T., Shirakawa, H., Nakagawa, T., and Kaneko, S. (2015). Activation of mitochondrial transient receptor potential vanilloid 1 channel contributes to microglial migration. Glia 63, 1870-1882. doi: 10.1002/glia.22854

Mizoguchi, Y., Kato, T. A., Seki, Y., Ohgidani, M., Sagata, N., Horikawa, H., et al. (2014). Brain-derived neurotrophic factor (BDNF) induces sustained intracellular $\mathrm{Ca}(2+)$ elevation through the up-regulation of surface transient receptor potential 3 (TRPC3) channels in rodent microglia. J. Biol. Chem. 289, 18549-18555. doi: 10.1074/jbc.M114.555334

Mosser, C. A., Baptista, S., Arnoux, I., and Audinat, E. (2017). Microglia in CNS development: Shaping the brain for the future. Prog. Neurobiol. 149-150, 1-20. doi: 10.1016/j.pneurobio.2017.01.002

Muffat, J., and Li, Y. (2016). Efficient derivation of microglia-like cells from human pluripotent stem cells. Nat. Med. 22, 1358-1367. doi: 10.1038/nm.4189 
Muffat, J., Li, Y., Yuan, B., Mitalipova, M., Omer, A., Corcoran, S., et al. (2016). Efficient derivation of microglia-like cells from human pluripotent stem cells. Nat. Med. 22, 1358-1367. doi: 10.1038/nm.41890

Naj, A. C., Jun, G., Beecham, G. W., Wang, L. S., Vardarajan, B. N., Buros, J., et al. (2011). Common variants at MS4A4/MS4A6E, CD2AP, CD33 and EPHA1 are associated with late-onset Alzheimer's disease. Nat. Genet. 43, 436-441. doi: $10.1038 /$ ng.801

Nathan, B. P., Bellosta, S., Sanan, D. A., Weisgraber, K. H., Mahley, R. W., and Pitas, R. E., (1994). Differential effects of apolipoproteins E3 and E4 on neuronal growth in vitro. Science 264, 850-852. doi: 10.1126/science.8171342

Nayak, D., Roth, T. L., and Mcgavern, D. B. (2014). Microglia development and function. Annu. Rev. Immunol. 32, 367-402. doi: 10.1146/annurev-immunol-032713-120240

Nguyen, H. M., Blomster, L. V., Christophersen, P., and Wulff, H. (2017a). Potassium channel expression and function in microglia: plasticity and possible species variations. Channels (Austin) 11, 305-315. doi: 10.1080/19336950.2017.1300738

Nguyen, H. M., Grossinger, E. M., Horiuchi, M., Davis, K. W., Jin, L. W., Maezawa, I., et al. (2017b). Differential Kv1.3, KCa3.1, and Kir2.1 expression in "classically" and "alternatively" activated microglia. Glia 65, 106-121. doi: $10.1002 /$ glia.23078

Nicholson, E., and Randall, A. D. (2009). Na(v)1.5 sodium channels in a human microglial cell line. J. Neuroimmunol. 215, 25-30. doi: 10.1016/j.jneuroim.2009.07.009

Nicoletti, N. F., Erig, T. C., Zanin, R. F., Roxo, M. R., Ferreira, N. P., Gomez, M. V., et al. (2017). Pre-clinical evaluation of voltage-gated calcium channel blockers derived from the spider P. nigriventer in glioma progression. Toxicon 129, 58-67. doi: 10.1016/j.toxicon.2017.02.001

Nilius, B., Prenen, J., Tang, J., Wang, C., Owsianik, G., Janssens, A., et al. (2005). Regulation of the $\mathrm{Ca}^{2+}$ sensitivity of the nonselective cation channel TRPM4. J. Biol. Chem. 280, 6423-6433. doi: 10.1074/jbc.M411089200

Nörenberg, W., Gebicke-Haerter, P. J., and Illes, P. (1994a). Voltage-dependent potassium channels in activated rat microglia. J. Physiol. 475, 15-32.

Nörenberg, W., Illes, P., and Gebicke-Haerter, P. J. (1994b). Sodium channel in isolated human brain macrophages (microglia). Glia 10, 165-172.

Novarino, G., Fabrizi, C., Tonini, R., Denti, M. A., Malchiodi-Albedi, F., Lauro, G. M., et al. (2004). Involvement of the intracellular ion channel CLIC1 in microglia-mediated beta-amyloid-induced neurotoxicity. J. Neurosci. 24, 5322-5330. doi: 10.1523/JNEUROSCI.1170-04.2004

Oakley, H., Cole, S. L., Logan, S., Maus, E., Shao, P., Craft, J., et al. (2006). Intraneuronal beta-amyloid aggregates, neurodegeneration, and neuron loss in transgenic mice with five familial Alzheimer's disease mutations: potential factors in amyloid plaque formation. J. Neurosci. 26, 10129-10140. doi: 10.1523/JNEUROSCI.1202-06.2006

Oddo, S., Caccamo, A., Shepherd, J. D., Murphy, M. P., Golde, T. E., Kayed, R., et al. (2003). Triple-transgenic model of Alzheimer's disease with plaques and tangles: intracellular Abeta and synaptic dysfunction. Neuron 39, 409-421. doi: 10.1016/S0896-6273(03)00434-3

Olah, M., Patrick, E., Villani, A.-C., Xu, J., White, C. C., Ryan, K. J., et al. (2018). A transcriptomic atlas of aged human microglia. Nat. Commun. 9:539. doi: 10.1038/s41467-018-02926-5

Pandya, H., Shen, M. J., Ichikawa, D. M., Sedlock, A. B., Choi, Y., Johnson, K. R., et al. (2017). Differentiation of human and murine induced pluripotent stem cells to microglia-like cells. Nat. Neurosci. 20, 753-759. doi: 10.1038/nn.4534

Pannasch, U., Farber, K., Nolte, C., Blonski, M., Yan Chiu, S., Messing, A., et al. (2006). The potassium channels Kv1.5 and Kv1.3 modulate distinct functions of microglia. Mol. Cell Neurosci. 33, 401-411. doi: 10.1016/j.mcn.2006. 08.009

Papavlassopoulos, M., Stamme, C., Thon, L., Adam, D., Hillemann, D., Seydel, U., et al. (2006). MaxiK blockade selectively inhibits the lipopolysaccharideinduced I kappa B-alpha /NF-kappa B signaling pathway in macrophages. J. Immunol. 177, 4086-4093. doi: 10.4049/jimmunol.177.6.4086

Pappalardo, L. W., Black, J. A., and Waxman, S. G. (2016). Sodium channels in astroglia and microglia. Glia 64, 1628-1645. doi: 10.1002/glia.22967

Paradisi, S., Matteucci, A., Fabrizi, C., Denti, M. A., Abeti, R., Breit, S. N., et al. (2008). Blockade of chloride intracellular ion channel 1 stimulates Abeta phagocytosis. J. Neurosci. Res. 86, 2488-2498. doi: 10.1002/jnr.21693
Payandeh, J., Scheuer, T., Zheng, N., and Catterall, W. A. (2011). The crystal structure of a voltage-gated sodium channel. Nature 475, 353-358. doi: $10.1038 /$ nature 10238

Peers, C., Pearson, H. A., and Boyle, J. P. (2007). Hypoxia and Alzheimer's disease. Essays Biochem. 43, 153-164. doi: 10.1042/bse0430153

Persson, A. K., Estacion, M., Ahn, H., Liu, S., Stamboulian-Platel, S., Waxman, S. G., et al. (2014). Contribution of sodium channels to lamellipodial protrusion and Racl and ERK1/2 activation in ATP-stimulated microglia. Glia 62, 2080-2095. doi: 10.1002/glia.22728

Plescher, M., Seifert, G., Hansen, J. N., Bedner, P., Steinhauser, C., and Halle, A. (2018). Plaque-dependent morphological and electrophysiological heterogeneity of microglia in an Alzheimer's disease mouse model. Glia 66, 1464-1480. doi: 10.1002/glia.23318

Poirier, J. (2005). Apolipoprotein E, cholesterol transport and synthesis in sporadic Alzheimer's disease. Neurobiol. Aging 26, 355-361. doi: 10.1016/j.neurobiolaging.2004.09.003

Ponomarev, E. D., Maresz, K., Tan, Y., and Dittel, B. N. (2007). CNS-derived interleukin-4 is essential for the regulation of autoimmune inflammation and induces a state of alternative activation in microglial cells. J. Neurosci. 27, 10714-10721. doi: 10.1523/JNEUROSCI.1922-07.2007

Raboune, S., Stuart, J. M., Leishman, E., Takacs, S. M., Rhodes, B., Basnet, A., et al. (2014). Novel endogenous $\mathrm{N}$-acyl amides activate TRPV1-4 receptors, BV-2 microglia, and are regulated in brain in an acute model of inflammation. Front. Cell Neurosci. 8:195. doi: 10.3389/fncel.2014.00195

Rangaraju, S., Dammer, E. B., Raza, S. A., Rathakrishnan, P., Xiao, H., Gao, T., et al. (2018). Identification and therapeutic modulation of a pro-inflammatory subset of disease-associated-microglia in Alzheimer's disease. Mol. Neurodegener. 13;24. doi: 10.1186/s13024-018-0254-8

Rangaraju, S., Gearing, M., Jin, L. W., and Levey, A. (2015). Potassium channel Kv1.3 is highly expressed by microglia in human Alzheimer's disease. J. Alzheimers Dis. 44, 797-808. doi: 10.3233/JAD-141704

Ribé, E. M., Perez, M., Puig, B., Gich, I., Lim, F., Cuadrado, M., et al. (2005). Accelerated amyloid deposition, neurofibrillary degeneration and neuronal loss in double mutant APP/tau transgenic mice. Neurobiol. Dis. 20, 814-822. doi: 10.1016/j.nbd.2005.05.027

Righi, M., Mori, L., De Libero, G., Sironi, M., Biondi, A., Mantovani, A., et al. (1989). Monokine production by microglial cell clones. Eur. J. Immunol. 19, 1443-1448. doi: 10.1002/eji.1830190815

Rowan, M. J., Klyubin, I., Wang, Q., Hu, N. W., and Anwyl, R. (2007). Synaptic memory mechanisms: Alzheimer's disease amyloid beta-peptide-induced dysfunction. Biochem. Soc. Trans. 35, 1219-1223. doi: 10.1042/BST0351219

Saegusa, H., and Tanabe, T. (2014). N-type voltage-dependent $\mathrm{Ca}^{2+}$ channel in non-excitable microglial cells in mice is involved in the pathophysiology of neuropathic pain. Biochem. Biophys. Res. Commun. 450, 142-147. doi: $10.1016 /$ j.bbrc. 2014.05 .103

Saijo, K., and Glass, C. K. (2011). Microglial cell origin and phenotypes in health and disease. Nat. Rev. Immunol. 11, 775-787. doi: 10.1038/ nri3086

Saliba, J., Daou, A., Damiati, S., Saliba, J., El-Sabban, M., and Mhanna, R., (2018). Development of microplatforms to mimic the in vivo architecture of CNS and PNS physiology and their diseases. Genes (Basel) 9:E285. doi: 10.3390/genes 9060285

Sappington, R. M., and Calkins, D. J. (2008). Contribution of TRPV1 to microgliaderived IL-6 and NFkappaB translocation with elevated hydrostatic pressure. Invest. Ophthalmol. Vis. Sci. 49, 3004-3017. doi: 10.1167/iovs.07-1355

Sawada, M., Suzumura, A., Hosoya, H., Marunouchi, T., and Nagatsu, T. (1999). Interleukin-10 inhibits both production of cytokines and expression of cytokine receptors in microglia. J. Neurochem. 72, 1466-1471. doi: 10.1046/j.1471-4159.1999.721466.x

Schilling, T., and Eder, C. (2007). Ion channel expression in resting and activated microglia of hippocampal slices from juvenile mice. Brain Res. 1186, 21-28. doi: 10.1016/j.brainres.2007.10.027

Schilling, T., and Eder, C. (2011). Amyloid-beta-induced reactive oxygen species production and priming are differentially regulated by ion channels in microglia. J. Cell Physiol. 226, 3295-3302. doi: 10.1002/jcp.22675

Schilling, T., and Eder, C. (2015). Microglial $\mathrm{K}^{+}$channel expression in young adult and aged mice. Glia 63, 664-672. doi: 10.1002/glia.22776 
Schilling, T., Quandt, F. N., Cherny, V. V., Zhou, W., Heinemann, U., Decoursey, T. E., et al. (2000). Upregulation of $\mathrm{Kv} 1.3 \mathrm{~K}^{+}$channels in microglia deactivated by TGF-beta. Am. J. Physiol. Cell Physiol. 279, C1123-1134. doi: 10.1152/ajpcell.2000.279.4.C1123

Schlichter, L. C., Sakellaropoulos, G., Ballyk, B., Pennefather, P. S., and Phipps, D. J., (1996). Properties of $\mathrm{K}^{+}$and $\mathrm{Cl}^{-}$channels and their involvement in proliferation of rat microglial cells. Glia 17, 225-236.

Schmidtmayer, J., Jacobsen, C., Miksch, G., and Sievers, J. (1994). Blood monocytes and spleen macrophages differentiate into microglia-like cells on monolayers of astrocytes: membrane currents. Glia 12, 259-267. doi: 10.1002/glia.440120403

Schmitz, A., Sankaranarayanan, A., Azam, P., Schmidt-Lassen, K., Homerick, D., Hansel, W., et al. (2005). Design of PAP-1, a selective small molecule Kv1.3 blocker, for the suppression of effector memory $\mathrm{T}$ cells in autoimmune diseases. Mol. Pharmacol. 68, 1254-1270. doi: 10.1124/mol.105.015669

Seok, J., Warren, H. S., Cuenca, A. G., Mindrinos, M. N., Baker, H. V., $\mathrm{Xu}, \mathrm{W}$., et al. (2013). Genomic responses in mouse models poorly mimic human inflammatory diseases. Proc. Natl. Acad. Sci. U. S.A. 110, 3507-3512. doi: 10.1073/pnas. 1222878110

Sheffield, L. G., Marquis, J. G., and Berman, N. E. (2000). Regional distribution of cortical microglia parallels that of neurofibrillary tangles in Alzheimer's disease. Neurosci. Lett. 285, 165-168. doi: 10.1016/S0304-3940(00)01037-5

Sheng, J. G., Mrak, R. E., and Griffin, W. S. (1997). Glial-neuronal interactions in Alzheimer disease: progressive association of IL-lalpha+ microglia and S100 $\beta+$ astrocytes with neurofibrillary tangle stages. J. Neuropathol. Exp. Neurol. 56, 285-290. doi: 10.1097/00005072-199703000-00007

Shibata, M., and Suzuki, N. (2017). Exploring the role of microglia in cortical spreading depression in neurological disease. J. Cereb. Blood Flow Metab. 37, 1182-1191. doi: 10.1177/0271678X17690537

Siddiqui, T., Lively, S., Ferreira, R., Wong, R., and Schlichter, L. C. (2014). Expression and contributions of TRPM7 and KCa2.3/SK3 channels to the increased migration and invasion of microglia in anti-inflammatory activation states. PLoS ONE 9:e106087. doi: 10.1371/journal.pone.0106087

Silei, V., Fabrizi, C., Venturini, G., Salmona, M., Bugiani, O., Tagliavini, F., et al. (1999). Activation of microglial cells by PrP and beta-amyloid fragments raises intracellular calcium through L-type voltage sensitive calcium channels. Brain Res. 818, 168-170. doi: 10.1016/S0006-8993(98)01272-4

Skaper, S.D., Facci, L., and Giusti, P. (2013). Intracellular ion channel CLIC1: involvement in microglia-mediated $\beta$-amyloid peptide (1-42) neurotoxicity. Neurochem. Res. 38, 1801-1808. doi: 10.1007/s11064-013-1084-2

Song, W., Hooli, B., Mullin, K., Jin, S. C., Cella, M., Ulland, T. K., et al. (2017). Alzheimer's disease-associated TREM2 variants exhibit either decreased or increased ligand-dependent activation. Alzheimers Dement. 13, 381-387. doi: 10.1016/j.jalz.2016.07.004

Spranger, M., Kiprianova, I., Krempien, S., and Schwab, S. (1998). Reoxygenation increases the release of reactive oxygen intermediates in murine microglia. J. Cereb. Blood Flow Metab. 18, 670-674. doi: 10.1097/00004647-199806000-00009

Steinert, M., and Grissmer, S. (1997). Novel activation stimulus of chloride channels by potassium in human osteoblasts and human leukaemic $\mathrm{T}$ lymphocytes. J. Physiol. 500(Pt. 3), 653-660.

Stewart, C. R., Stuart, L. M., Wilkinson, K., Van Gils, J. M., Deng, J., Halle, A., et al. (2010). CD36 ligands promote sterile inflammation through assembly of a Toll-like receptor 4 and 6 heterodimer. Nat. Immunol. 11, 155-161. doi: $10.1038 /$ ni. 1836

Stock, C., Schilling, T., Schwab, A., and Eder, C. (2006). Lysophosphatidylcholine stimulates IL-1beta release from microglia via a P2X7 receptor-independent mechanism. J. Immunol. 177, 8560-8568. doi: 10.4049/jimmunol.177. 12.8560

Sun, C.-K., Zhen, Y.-Y., Lu, H.-I., Sung, P.-H., Chang, L.-T., Tsai, T.-H., et al. (2014). Reducing TRPC1 expression through liposome-mediated siRNA delivery markedly attenuates hypoxia-induced pulmonary arterial hypertension in a murine model. Stem Cells Int. 2014:316214. doi: $10.1155 / 2014 / 316214$

Szalay, G., Martinecz, B., Lenart, N., Kornyei, Z., Orsolits, B., Judak, L., et al. (2016). Microglia protect against brain injury and their selective elimination dysregulates neuronal network activity after stroke. Nat. Commun. 7:11499. doi: 10.1038/ncomms11499
Takahashi, K., and Yamanaka, S. (2006). Induction of pluripotent stem cells from mouse embryonic and adult fibroblast cultures by defined factors. Cell 126, 663-676. doi: 10.1016/j.cell.2006.07.024

Takao, K., and Miyakawa, T. (2015). Genomic responses in mouse models greatly mimic human inflammatory diseases. Proc. Natl. Acad. Sci. U. S.A. 112, 1167-1172. doi: 10.1073/pnas.1401965111

Takata, K., Kozaki, T., Lee, C. Z.W., Thion, M. S., Otsuka, M., Lim, S., et al. (2017). Induced-pluripotent-stem-cell-derived primitive macrophages provide a platform for modeling tissue-resident macrophage differentiation and function. Immunity 47, 183-198 e186. doi: 10.1016/j.immuni.2017.06.017.

Talbot, S., Dias, J. P., Lahjouji, K., Bogo, M. R., Campos, M. M., Gaudreau, P., et al. (2012). Activation of TRPV1 by capsaicin induces functional kinin B(1) receptor in rat spinal cord microglia. J. Neuroinflammation 9:16. doi: $10.1186 / 1742-2094-9-16$

Tarcha, E. J., Chi, V., Munoz-Elias, E. J., Bailey, D., Londono, L. M., Upadhyay, S. K., et al. (2012). Durable pharmacological responses from the peptide ShK-186, a specific Kv1.3 channel inhibitor that suppresses T cell mediators of autoimmune disease. J. Pharmacol. Exp. Ther. 342, 642-653. doi: 10.1124/jpet.112.191890

Tian, D. S., Li, C. Y., Qin, C., Murugan, M., Wu, L. J., and Liu, J. L. (2016), Deficiency in the voltage-gated proton channel Hv1 increases M2 polarization of microglia and attenuates brain damage from photothrombotic ischemic stroke. J. Neurochem. 139, 96-105. doi: 10.1111/jnc.13751

Toescu, E. C., Moller, T., Kettenmann, H., and Verkhratsky, A. (1998). Long-term activation of capacitative $\mathrm{Ca}^{2+}$ entry in mouse microglial cells. Neuroscience 86 , 925-935. doi: 10.1016/S0306-4522(98)00123-7

Tsai, K. L., Chang, H. F., and Wu, S. N. (2013). The inhibition of inwardly rectifying $\mathrm{K}^{+}$channels by memantine in macrophages and microglial cells. Cell Physiol. Biochem. 31, 938-951. doi: 10.1159/000350112

Uchida, K., Dezaki, K., Damdindorj, B., Inada, H., Shiuchi, T., Mori, Y., et al. (2011). Lack of TRPM2 impaired insulin secretion and glucose metabolisms in mice. Diabetes 60, 119-126. doi: 10.2337/db10-0276

Ulland, T. K., Song, W. M., Huang, S. C., Ulrich, J. D., Sergushichev, A., Beatty, W. L., et al. (2017). TREM2 maintains microglial metabolic fitness in Alzheimer's disease. Cell 170, 649-663 e613. doi: 10.1016/j.cell.2017.07.023.

Ulrich, J. D., Finn, M. B., Wang, Y., Shen, A., Mahan, T. E., Jiang, H., et al. (2014). Altered microglial response to Abeta plaques in APPPS1-21 mice heterozygous for TREM2. Mol. Neurodegener. 9:20. doi: 10.1186/1750-1326-9-20

Ulrich, J. D., Ulland, T. K., Colonna, M., and Holtzman, D. M. (2017). Elucidating the role of TREM2 in Alzheimer's disease. Neuron 94, 237-248. doi: 10.1016/j.neuron.2017.02.042

Valerie, N. C., Dziegielewska, B., Hosing, A. S., Augustin, E., Gray, L. S., Brautigan, D. L., et al. (2013). Inhibition of T-type calcium channels disrupts Akt signaling and promotes apoptosis in glioblastoma cells. Biochem. Pharmacol. 85, 888-897. doi: 10.1016/j.bcp.2012.12.017

Visentin, S., Agresti, C., Patrizio, M., and Levi, G. (1995). Ion channels in rat microglia and their different sensitivity to lipopolysaccharide and interferongamma. J. Neurosci. Res. 42, 439-451. doi: 10.1002/jnr.490420402

Walz, W., Ilschner, S., Ohlemeyer, C., Banati, R., and Kettenmann, H. (1993). Extracellular ATP activates a cation conductance and a $\mathrm{K}^{+}$conductance in cultured microglial cells from mouse brain. J. Neurosci. 13, 4403-4411. doi: 10.1523/JNEUROSCI.13-10-04403.1993

Wang, Y., Cella, M., Mallinson, K., Ulrich, J. D., Young, K. L., Robinette, M. L., et al. (2015). TREM2 lipid sensing sustains the microglial response in an Alzheimer's disease model. Cell 160, 1061-1071. doi: 10.1016/j.cell.2015.01.049

Wen, Z., Christian, K. M., Song, H., and Ming, G. L. (2016). Modeling psychiatric disorders with patient-derived iPSCs. Curr. Opin. Neurobiol. 36, 118-127. doi: 10.1016/j.conb.2015.11.003

Wendt, S., Maricos, M., Vana, N., Meyer, N., Guneykaya, D., Semtner, M., et al. (2017). Changes in phagocytosis and potassium channel activity in microglia of $5 \mathrm{xFAD}$ mice indicate alterations in purinergic signaling in a mouse model of Alzheimer's disease. Neurobiol. Aging 58, 41-53. doi: 10.1016/j.neurobiolaging.2017.05.027

Wes, P. D., Easton, A., Corradi, J., Barten, D. M., Devidze, N., Decarr, L. B., et al. (2014). Tau overexpression impacts a neuroinflammation gene expression network perturbed in Alzheimer's disease. PLOS ONE 9:e106050. doi: 10.1371/journal.pone.0106050 
Wolfe, M. S. (2012). The role of tau in neurodegenerative diseases and its potential as a therapeutic target. Scientifica 2012:796024. doi: 10.6064/2012/796024

Wright, A. L., Zinn, R., Hohensinn, B., Konen, L. M., Beynon, S. B., Tan, R. P., et al. (2013). Neuroinflammation and neuronal loss precede Abeta plaque deposition in the hAPP-J20 mouse model of Alzheimer's disease. PLoS ONE 8:e59586. doi: 10.1371/journal.pone.0059586

Wu, L. J., Wu, G., Akhavan Sharif, M. R., Baker, A., Jia, Y., Fahey, F. H., et al. (2012). The voltage-gated proton channel Hvl enhances brain damage from ischemic stroke. Nat. Neurosci. 15, 565-573. doi: 10.1038/nn.3059

Wu, W. K., Li, G. R., Wong, H. P., Hui, M. K., Tai, E. K., Lam, E. K., et al. (2006). Involvement of Kv1.1 and Nav1.5 in proliferation of gastric epithelial cells. J. Cell Physiol. 207, 437-444. doi: 10.1002/jcp.20576

$\mathrm{Wu}, \mathrm{Y}$. P., and Ling, E. A. (1998). Induction of microglial and astrocytic response in the adult rat lumbar spinal cord following middle cerebral artery occlusion. Exp. Brain Res. 118, 235-242. doi: 10.1007/s002210050277

Yamanaka, S. (2009). A fresh look at iPS cells. Cell 137, 13-17. doi: 10.1016/j.cell.2009.03.034

Yamasaki, R., Lu, H., Butovsky, O., Ohno, N., Rietsch, A. M., Cialic, R., et al. (2014). Differential roles of microglia and monocytes in the inflamed central nervous system. J. Exp. Med. 211, 1533-1549. doi: 10.1084/jem.20132477

Yin, Z., Raj, D., Saiepour, N., Van Dam, D., Brouwer, N., Holtman, I. R., et al. (2017). Immune hyperreactivity of Abeta plaque-associated microglia in Alzheimer's disease. Neurobiol. Aging 55, 115-122. doi: 10.1016/j.neurobiolaging.2017.03.021

Yoshiyama, Y., Higuchi, M., Zhang, B., Huang, S. M., Iwata, N., Saido, T. C., et al. (2007). Synapse loss and microglial activation precede tangles in a P301S tauopathy mouse model. Neuron 53, 337-351. doi: $10.1016 /$ j.neuron.2007.01.010
Yuan, P., Condello, C., Keene, C. D., Wang, Y., Bird, T. D., Paul, S. M., et al. (2016). TREM2 haplodeficiency in mice and humans impairs the microglia barrier function leading to decreased amyloid compaction and severe axonal dystrophy. Neuron 92, 252-264. doi: 10.1016/j.neuron.2016. 09.016

Zhang, B., Gaiteri, C., Bodea, L. G., Wang, Z., Mcelwee, J., Podtelezhnikov, A. A., et al. (2013). Integrated systems approach identifies genetic nodes and networks in late-onset Alzheimer's disease. Cell 153, 707-720. doi: 10.1016/j.cell.2013.03.030

Zheng, C., Zhou, X.-W., and Wang, J.-Z. (2016). The dual roles of cytokines in Alzheimer's disease: update on interleukins, TNF- $\alpha$, TGF$\beta$ and IFN- $\gamma$. Transl. Neurodegener. 5:7. doi: 10.1186/s40035-0160054-4

Zlokovic, B. V. (2013). Cerebrovascular effects of apolipoprotein E: implications for Alzheimer disease. J. Am. Med. Assoc. Neurol 70, 440-444. doi: 10.1001/jamaneurol.2013.2152

Conflict of Interest Statement: The authors declare that the research was conducted in the absence of any commercial or financial relationships that could be construed as a potential conflict of interest.

Copyright (๑) 2018 Thei, Imm, Kaisis, Dallas and Kerrigan. This is an open-access article distributed under the terms of the Creative Commons Attribution License (CC $B Y)$. The use, distribution or reproduction in other forums is permitted, provided the original author(s) and the copyright owner(s) are credited and that the original publication in this journal is cited, in accordance with accepted academic practice. No use, distribution or reproduction is permitted which does not comply with these terms. 